\title{
Dietary Polyphenol Supplementation Prevents Alterations of Spatial Navigation in Middle-Aged Mice
}

\author{
Julien Bensalem ${ }^{1,2,3}$, Laure Servant ${ }^{1,2}$, Serge Alfos ${ }^{1,2,4}$, David Gaudout ${ }^{3}$, Sophie Layé ${ }^{1,2}$, \\ Véronique Pallet ${ }^{1,2,4 * t}$ and Pauline Lafenetre ${ }^{1,2,4 * t}$ \\ ${ }^{1}$ Nutrition et Neurobiologie Intégrée, Université de Bordeaux, UMR 1286, Bordeaux, France, ${ }^{2}$ INRA, Nutrition et \\ Neurobiologie Intégrée, UMR 1286, Bordeaux, France, ${ }^{3}$ Activ'Inside, Libourne, France, ${ }^{4}$ Nutrition et Neurobiologie Intégrée, \\ Bordeaux INP, UMR 1286, Bordeaux, France
}

\section{OPEN ACCESS}

Edited by:

Johannes Gräff,

École Polytechnique Fédérale de Lausanne, Switzerland

Reviewed by:

Ashok K. Shetty,

Texas A\&M Health Science Center

College of Medicine, USA Amy Pooler,

Nestlé Institute of Health Sciences,

Switzerland

*Correspondence:

Pauline Lafenetre pauline.lafenetre@bordeaux-inp.fr; Véronique Pallet veronique.pallet@enscbp.fr

+ These authors have equally contributed to the work.

Received: 12 October 2015 Accepted: 25 January 2016 Published: 09 February 2016

Citation: Bensalem J, Servant L, Alfos S, Gaudout $D$, Layé $S$, Pallet $V$ and Lafenetre P (2016) Dietary Polyphenol Supplementation Prevents Alterations of Spatial Navigation in Middle-Aged Mice. Front. Behav. Neurosci. 10:9. doi: 10.3389/fnbeh.2016.00009
Spatial learning and memory deficits associated with hippocampal synaptic plasticity impairments are commonly observed during aging. Besides, the beneficial role of dietary polyphenols has been suggested as potential functional food candidates to prevent this memory decline. Indeed, polyphenols could potentiate the signaling pathways of synaptic plasticity underlying learning and memory. In this study, spatial learning deficits of middle-aged mice were first highlighted and characterized according to their navigation patterns in the Morris water maze task. An eight-week polyphenol-enriched diet, containing a polyphenol-rich extract from grape and blueberry (PEGB; from the Neurophenols Consortium) with high contents of flavonoids, stilbenes and phenolic acids, was then successful in reversing these age-induced effects. The use of spatial strategies was indeed delayed with aging whereas a polyphenol supplementation could promote the occurrence of spatial strategies. These behavioral results were associated with neurobiological changes: while the expression of hippocampal calmodulin kinase II (CaMKII) mRNA levels was reduced in middle-aged animals, the polyphenol-enriched diet could rescue them. Besides, an increased expression of nerve growth neurotrophic factor (NGF) mRNA levels was also observed in supplemented adult and middle-aged mice. Thus these data suggest that supplementation with polyphenols could be an efficient nutritional way to prevent age-induced cognitive decline.

Keywords: age, hippocampus, berries, polyphenols, learning and memory, strategy, navigation

\section{INTRODUCTION}

Aging is associated with cognitive impairments and increased risks of neurodegenerative disorders such as Alzheimer's disease which may contribute to the loss of the ability to live independently (Evans et al., 1989). In this context it seems paramount to better understand the effects of aging on learning and memory and to develop new strategies to prevent or counteract the age-associated memory decline.

The hippocampus is one of the brain structures involved in spatial learning and memory which is particularly affected during aging (Erickson and Barnes, 2003). These impairments have been observed not only in rodents (Barnes, 1979; Markowska et al., 1989; Gallagher and Rapp, 1997; Bach et al., 1999) but also in monkeys (Lai et al., 1995; Gallagher and Rapp, 1997) and in humans (Uttl and Graf, 1993; Wilkniss et al., 1997; Gazova et al., 2013). Indeed, in a 
real-space adapted version of the Morris water maze for humans, it has been shown that the profile of allocentric (world-centered, hippocampus-dependent) spatial navigation learning, but not egocentric navigation, is particularly altered in adults over 70 (Gazova et al., 2013). The age-related profile of spatial navigation has also been studied in mice in the star maze and in the Morris water maze (Martel et al., 2007; Fouquet et al., 2011). Although it is accepted that aged mice (over 17 months old) abandon sequential egocentric and/or allocentric (hippocampusdependent) strategies in favor of egocentric or cued (striatumdependent) strategies (Kim et al., 2001; Martel et al., 2007), the training protocols (massed vs. spaced) may influence the adoption of a strategy over another. Indeed, these studies cannot fully translate the parallel and progressive acquisition of nonspatial to spatial strategies that are observed in the Morris water maze (Janus, 2004; Brody and Holtzman, 2006; Stone et al., 2011; Ruediger et al., 2012), and that depends on the interaction of multiple memory systems (Gazova et al., 2013). It is thus of interest to further analyze how aging may influence this evolution (Gil-Mohapel et al., 2013) and the differential use of non-spatial and spatial strategies by middle-aged and aged animals. The neurobiological basis for differences in navigation patterns is not fully understood but based on previous studies it is possible to hypothesize that differential activations of the hippocampus and the striatum during the learning phase could explain this evolution. Indeed, the hippocampus and the striatum must act in parallel during the acquisition of the task (Colombo et al., 2003; Martel et al., 2007).

Long-term memories are associated with molecular changes (Carew, 1996; Kandel, 2001; Sossin, 2008), such as the synthesis of new mRNAs and proteins (Martin et al., 2000; Kelleher et al., 2004; Bramham and Wells, 2007). Various signaling pathways involved in the control of de novo protein synthesis such as extracellular signal regulated kinase (ERK) (Sweatt, 2001, 2004) converge to the activation of the transcription factor cAMP-response element-binding protein (CREB) which binds the promoter regions of many genes associated with synaptic plasticity underlying spatial learning and memory (Harris and Kater, 1994; Impey et al., 1996, 1998, 2004; Pham et al., 1999; Barco et al., 2006; Alvarez and Sabatini, 2007). Hippocampal levels of phosphorylated calmodulin kinase II (CaMKII), known to regulate the phosphorylation of CREB (Dash et al., 1991), are reduced in aged animals relative to young animals. CREB also regulates the transcription of neurotrophins, such as brain derived neurotrophic factor (BDNF) or nerve growth neurotrophic factor (NGF), implicated not only in neuronal survival, outgrowth and differentiation (Finkbeiner et al., 1997; Finkbeiner, 2000; Schinder and Poo, 2000; Conkright et al., 2003; Pruunsild et al., 2011) but also in the control of synaptic plasticity and long-term memory (Poo, 2001; Bramham and Messaoudi, 2005; Calabrese et al., 2009). Similarly, the use of non-spatial strategies could trigger their expression in the striatum.

There is increasing evidence of how dietary habits or nutrients may exert beneficial effects on brain aging. Among "functional foods" promoting a healthy aging, fruits and vegetables rich in polyphenols are now highly studied for their potential beneficial effects on memory (Shukitt-Hale et al., 2008; Rendeiro et al., 2009; Kean et al., 2015). Within the polyphenol family, flavonoids have been shown to ameliorate learning and memory in both animals and humans. Flavanols, and particularly epicatechin and catechin, present in grape seeds, green tea or cocoa for example, have been shown to ameliorate learning and memory in animals (Devi et al., 2006; Haque et al., 2006; van Praag et al., 2007; Kaur et al., 2008; Asha Devi et al., 2011; Rendeiro et al., 2013b) and in humans (Dinges, 2006). Anthocyanins, present in red berries as in blueberries, have also been shown to prevent memory deficits in aged animals (Cho et al., 2003; Ramirez et al., 2005; Barros et al., 2006; Shukitt-Hale et al., 2006; Rendeiro et al., 2013b). About flavanols, quercetin has been undoubtedly the most extensively studied flavonol in their neuroprotective potential in vivo (Dajas et al., 2003, 2013; Rivera et al., 2004; Ahmad et al., 2011). Clinical studies have also observed an improvement of memory in older people with a supplementation with grape juice or with blueberry juice rich in flavonoids (Krikorian et al., 2010a,b, 2012). Moreover, flavonoid consumption has been associated with better cognitive performance in an epidemiological study over 10 years (Letenneur et al., 2007). Stilbenes and more precisely resveratrol, found mainly in grapes and wine, have displayed beneficial effects on learning and memory in animals (Abraham and Johnson, 2009; Dal-Pan et al., 2011; Harada et al., 2011; Kodali et al., 2015) and in humans (Witte et al., 2014). A naturally dimethylated analog of resveratrol, pterostilbene found in blueberries (Aiyer et al., 2012) and grapes (Adrian et al., 2000), exhibits similar biological activities (Rimando et al., 2002) and have been reported to be effective in reversing cognitive deficits in aged rats (Joseph et al., 2008). Phenolic acids are a very large polyphenols family as most of them can be the results of the microbial metabolism of other polyphenols (Margalef et al., 2014). Phenolic acids have also displayed beneficial effect to reverse memory impairments (Yan et al., 2001; Vauzour et al., 2007). Interestingly, polyphenols are not only able to impact on learning and memory during aging but they can also modulate neuronal signaling cascades altered with aging. Thereby, polyphenols may act on ERK/CREB pathway involved in synaptic plasticity and long-term potentiation (Williams and Grayer, 2004; Schroeter et al., 2007; Vauzour et al., 2007; Rendeiro et al., 2009). Indeed, flavonoid supplementations can modulate specific signaling kinases like CaMKII (Abraham and Johnson, 2009; Rendeiro et al., 2009), and ERK (Rendeiro et al., 2009, 2013a), controlling the activation of CREB and the increased expression of BDNF (Abraham and Johnson, 2009; Rendeiro et al., 2009, 2013a; De Nicoló et al., 2013) and of NGF (De Nicoló et al., 2013) in the hippocampus. Some studies have also reported that polyphenols, among them flavanols, anthocyanins or resveratrol, are found in the brain tissue after oral ingestion (Abd El Mohsen et al., 2002, 2006; Asensi et al., 2002; Andres-Lacueva et al., 2005; Williams et al., 2008; Prasain et al., 2009; Juan et al., 2010; Milbury and Kalt, 2010). The possible existence of specific polyphenol binding sites at the cellular plasma membrane level in the rat brain has been suggested (Han et al., 2006). 
While flavonoids and stilbenes, present in berry extracts, have potential properties against age-related cognitive decline, their specific benefits on spatial navigation patterns are unknown.

In this study, we investigated the effects of age and of a polyphenol-rich extract from grape and blueberry (PEGB; from the Neurophenols Consortium) supplementation, with high contents of flavonoids, on hippocampus-dependent learning and memory processes. First, the learning and memory deficits observed in middle-aged mice were better characterized according to their navigation patterns in the Morris water maze, then, the effectiveness of dietary polyphenols in the prevention of age-associated memory decline was assessed and the neurobiological correlates underlying these effects were investigated.

\section{MATERIALS AND METHODS}

\section{Animals and Diet}

For this study 20 adult (6-week old) and 24 middle-aged (16-month old) male C57Bl/6J mice were purchased from Janvier (France). They were singly housed in a room with a constant airflow system, controlled temperature $\left(21-23^{\circ} \mathrm{C}\right)$, and a $12 \mathrm{~h}$ light/dark cycle. Mice were given ad libitum access to food and water. Naïve mice were randomly divided into four experimental groups (Figure 1A). One group of adult mice $(n=10)$ and one of middle-aged mice $(n=12)$ were fed with a control diet (INRA Jouy-en-Josas, France), whereas the two other groups of adult mice $(n=10)$ and middle-aged mice $(n=12)$ received a PEGBenriched diet (INRA Jouy-en-Josas, France) containing $500 \mathrm{mg}$ of $\mathrm{PEGB} / \mathrm{kgbw} /$ day (provided by the Neurophenols Consortium). The composition of the PEGB-enriched pellets was the same as the control pellets, except for the polyphenol content (Table 1). Diets started as soon as mice arrived in the laboratory (i.e., at the age of 6 weeks for adult mice and 16 months for middleaged mice) and continued throughout the entire experiment (8 weeks). Thereby, at the end of the experiment adult mice were 3.5 months old and middle-aged mice were 18 months old. The PEGB is a powder made of grape (Vitis vinifera L.; Activ'Inside, France) and blueberry (Vaccinium angustifolium; NutraCanada, Canada) extracts containing specific polyphenols with low molecular weight (flavanols monomers and oligomers, flavonols, anthocyanins, phenolic acids and resveratrol) formulated in a unique ratio of molecules. The $500 \mathrm{mg}$ of $\mathrm{PEGB} / \mathrm{kgbw} /$ day dose was determined by a literature review and proportions for each polyphenol class of interest were adjusted in the mix. This specific ratio of polyphenols remains confidential. All experiments were performed in accordance with the European Communities

\section{A Experimental groups}

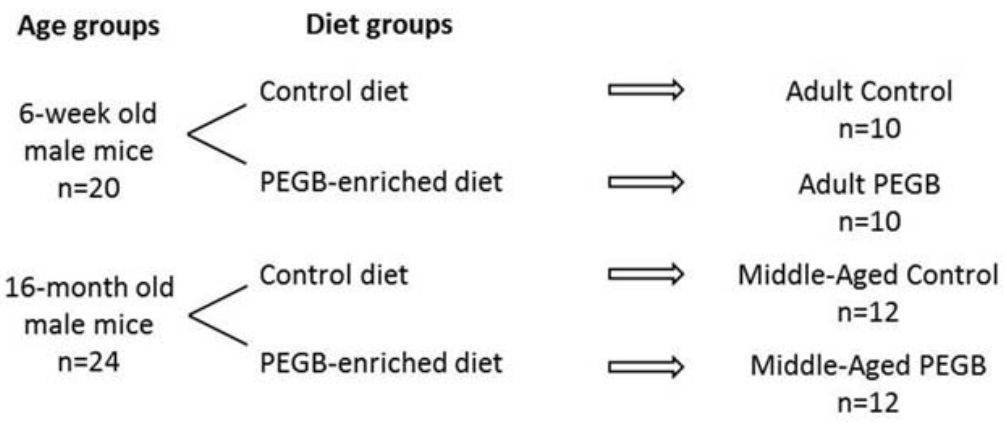

\section{B Morris water maze procedure}

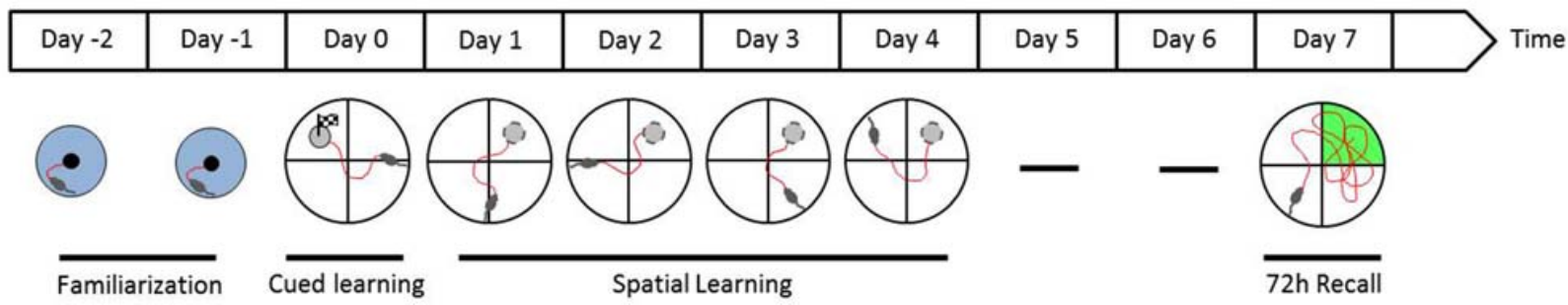

FIGURE 1 | Experimental design. (A) Six-week old and sixteen-month old mice were either fed a control diet or a polyphenol-enriched diet (500 mg of PEGB/kgbw/day) for 8 weeks (i.e., 6 weeks before performing the Morris water maze test). (B) A 2-day familiarization period was performed before the 1-day cued learning. Spatial learning has then been evaluated over 4 days. Seventy two hours after the last learning trial a probe test was performed in order to evaluate spatial memory. 
TABLE 1 | Composition of the control and the PEGB-enriched diets.

\begin{tabular}{lcc}
\hline & \multicolumn{2}{c}{ Percent (\%) } \\
\cline { 2 - 3 } Components & Control diet & PEGB-enriched diet \\
\hline Hydrochloric casein & 18 & 18 \\
Corn starch & 40 & 45 \\
Sucrose & 29.9 & 24.39 \\
Cellulose & 2 & 2 \\
Peanut oil & 2.5 & 2.5 \\
Rapeseed oil & 2.5 & 2.5 \\
Mineral coumpoud 102 & 4 & 4 \\
Vitamin coumpoud 102 & 1 & 1 \\
without vitamine A & - & - \\
+ DL methionine & 0.1 & 0.1 \\
+ Vitamin A 5 UI/g & $5 U \mathrm{Ul} / \mathrm{g}$ & 0.51 \\
PEGB & 0 &
\end{tabular}

PEGB extract was introduced at $0.51 \%$ in the diet pellets.

Council Directives (86/609/EEC) and the French national Committee (87/848) recommendations, and have been approved by the Animal Care and Use Committee of Bordeaux under the $\mathrm{N}^{\circ} 5012085-\mathrm{A}$.

\section{Body Weight and Food Intake}

Body weight and food intake were monitored weekly during the 8 -week supplementation period.

\section{Spatial Learning and Reference Memory in the Morris Water Maze}

\section{Training Phase}

Six weeks after the beginning of the diets, spatial learning and memory were assessed in a Morris water maze $(150 \mathrm{~cm}$ in diameter, $50 \mathrm{~cm}$-high) filled with white water $\left(22^{\circ} \mathrm{C}\right)$ and surrounded with distal extramaze cues (Figure 1B). Before being trained, animals were handled $1 \mathrm{~min}$ a day for 2 days. Mice were then familiarized to water and swimming during two familiarization days (day-1 and day-2) where they had to find a visible platform in the center of a small pool $(60 \mathrm{~cm}$ diameter) surrounded with curtains (three consecutive trials a day; $60 \mathrm{~s}-$ cut-off). On day 0 , to evaluate visuomotor deficits, mice were given six trials (90 s-cut-off) to find a visible platform pointed out with a cue in the Morris water maze that was surrounded with white curtains. During the training sessions (days 1-4), animals were required to locate the submerged platform by using distal extramaze cues. They were trained for six trials a day (90 scut-off) with an intertrial interval of 5 min for four consecutive days. In order to facilitate spatial learning, mice were introduced from four different starting points, in a randomized daily order. The speed, the latency and the distance to reach the platform as well as the swim path of each trial were recorded by Imetronics videotracking system (France). The daily swim path efficiency was calculated as the ratio of the shortest possible length to the effective swim path length.

\section{Probe Test}

Seventy two hours after the last training session, the platform was removed from the pool and spatial memory was evaluated for $60 \mathrm{~s}$. The percentage of distance traveled in the four quadrants was recorded using the SMART system (San Diego Instruments). The quadrant where the platform was located during training is referred to as target quadrant. Additionally, the number of annulus crossings and the mean proximity to the platform were assessed during this test as reliable measures of probe test performance (Maei et al., 2009).

\section{Analysis of Navigation Strategies}

For each trial of the training phase, the navigation path was analyzed from the replay of the videotracking system (Imetronics, France) and assigned to one of the eleven strategies by two experimenters, blind to the groups. The categorization scheme (see Figure 4A) was adapted from those developed previously (Brody and Holtzman, 2006; Garthe et al., 2009; Stone et al., 2011; Ruediger et al., 2012). These strategies were divided into two main categories: non-spatial vs. spatial strategies. Non-spatial strategies included first "global search" strategies: "peripheral looping" (persistent swimming around the outer $15 \mathrm{~cm}$ of the pool, including thigmotaxis), "random" (searching the entire tank, $>75 \%$ surface coverage), "circling" (swimming in tight circles, possibly with some net directional movement), and then "local search" strategies: "scanning" (searching restricted to a limited, often central, portion of the tank, $>15 \%$ and $<75 \%$ of surface coverage), "chaining" (circular swimming at an approximately fixed distance greater than $15 \mathrm{~cm}$ from the wall), "repeated incorrect" (swimming in a precise direction that does not contain the platform and repeat the same trajectory several times), and "focal incorrect" (searching intently a small portion of the tank that does not contain the platform). Spatial strategies included "repeated correct" (swimming in direction of the platform and repeat the same trajectory several times), "focal correct" (swimming and searching intently in the zone containing the platform), "spatial indirect" (swimming indirectly to the platform with eventually 1-2 loops) and "spatial direct" (swimming directly to the platform).

\section{Tissue Preparation}

Ninety minutes after the probe test, mice were euthanized by cervical dislocation and decapitated. Brains were rapidly removed and hippocampi were dissected and frozen with liquid nitrogen before being stored at $-80^{\circ} \mathrm{C}$ until assay.

\section{Quantitative Real-Time PCR Analysis}

Hippocampal and striatal gene expression were measured as previously described (Touyarot et al., 2013). RNA extraction was conducted using TRIzol reagent kit (Invitrogen, France) according to the manufacturer's instructions. The integrity of the purified RNA was verified using the RNA 6000 Nano LabChip kit in combination with the 2100 Bioanalyzer (Agilent Technologies, France). The concentrations of RNA were determined by using a Nanodrop ND-1000 (Labtech, France). Using oligodT and random primers (Promega, France), cDNA was synthesized from $1 \mu \mathrm{g}$ of RNA with ImPromII reverse transcriptase (Promega, France) according to the manufacturer's protocol. Briefly, $1 \mu \mathrm{g}$ 


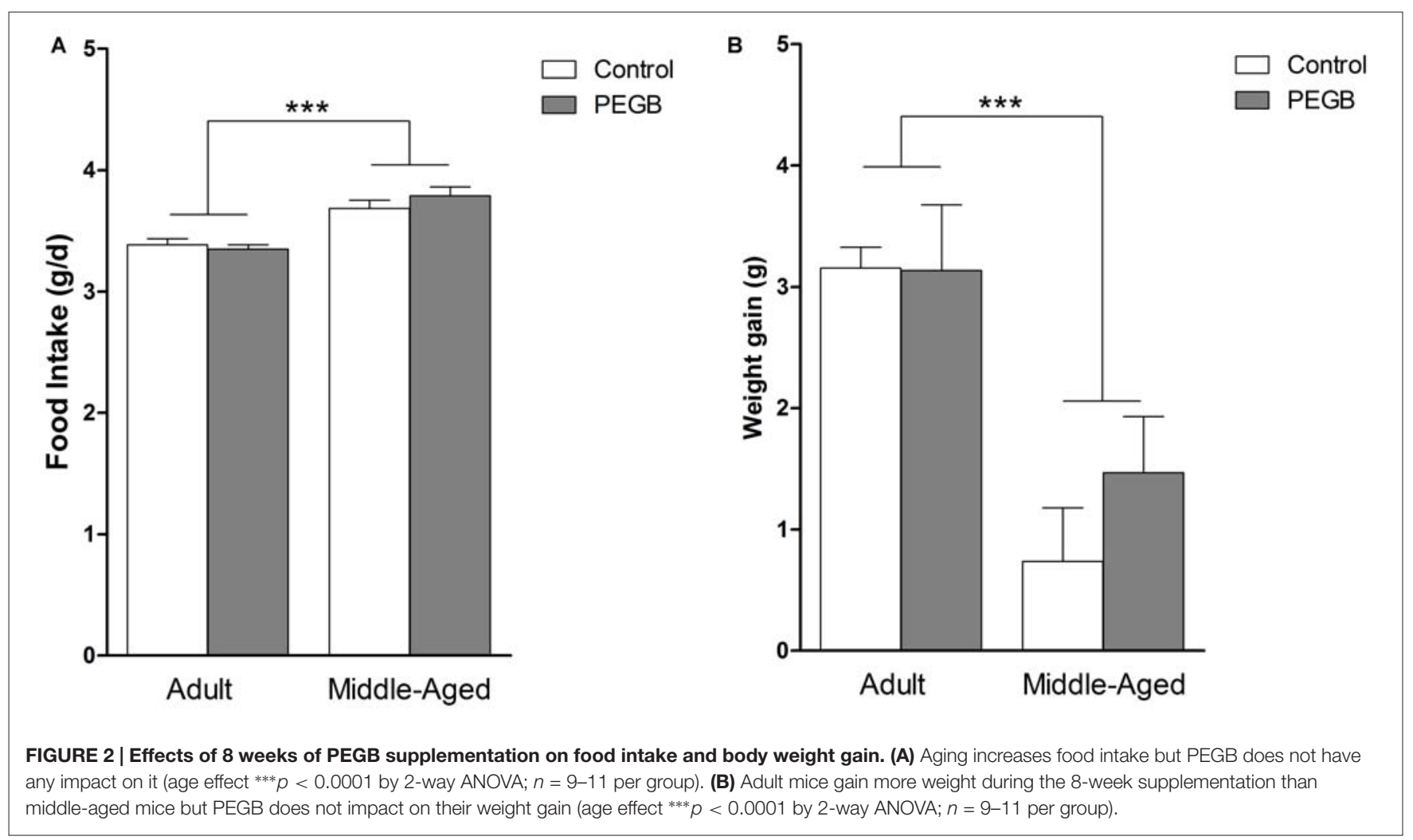

of total RNA mixed with RNasin (Promega) and DNase (Roche) was incubated at $37^{\circ} \mathrm{C}$. Then, OligodT and random primers were added for incubation at $70^{\circ} \mathrm{C}$. The reverse transcriptase reaction was performed at $42^{\circ} \mathrm{C}$ for $60 \mathrm{~min}$ in a final volume of $20 \mu \mathrm{l}$.

The real-time PCR was performed using the LightCycler 480 system with a 96-well format (Roche Diagnostics, Germany) in a volume of $20 \mu \mathrm{L}$, containing $1 \times$ LightCycler 480 SYBR Green I Master solution, $0.5 \mu \mathrm{M}$ of each primer and $6 \mu \mathrm{L}$ of $\mathrm{cDNA}$. The forward and reverse primer sequences and the amplicon size Actin, NGF, BDNF, CaMKII, ERK1 and ERK2 are summarized in Table 2. Actin was used as the reference gene since its expression level was unaffected in our experimental conditions. The following program started with an initial denaturation step for $10 \mathrm{~min}$ at $95^{\circ} \mathrm{C}$, then an amplification for 40 cycles $(10 \mathrm{~s}$ denaturation at $95^{\circ} \mathrm{C}, 6 \mathrm{~s}$ annealing at $62^{\circ} \mathrm{C}$, and $10 \mathrm{~s}$ extension at $72^{\circ} \mathrm{C}$ ), finally a melting curve analysis was run. In order to verify the specificity and the identity of the amplified products: (1) the melting curve analysis showed a single melting peak after amplification; and (2) amplified products for each gene were verified by sequencing with the Big Dye Terminator v1.1. (Applied Biosystems) and analyzed on a ABI3130 sequencer (Applied Biosystems).

Quantification data were analyzed using the LightCycler 480 Relative Quantification software (version 1.5). In order to compensate for differences in target and reference gene amplification efficiency, either within or between experiments, this software provides a calibrator-normalized relative quantification including a PCR efficiency correction. Therefore, the results are expressed as the target/reference ratio divided by the target/reference ratio of the calibrator. In our case, the calibrator was chosen among the adult mice.

\section{Statistical Analysis}

Statistical analyses were performed using StatView ${ }^{\circledR}$ (SAS Institute Inc., USA). Graphical representations were performed using GraphPad Prism ${ }^{\circledR}$. Results were considered significantly

TABLE 2 | Forward and reverse primer sequences and amplicon size used for LightCycler RT-qPCR.

\begin{tabular}{llc}
\hline Gene name & Nucleotide sequence 5'-3' $^{\prime}$ & Amplicon size (bp) \\
\hline Actin & F: AAAACGCAGCTCAGTAACAGTCC & 220 \\
& R: AGGATGCAGAAGGAGATTACTGC & \\
NGF & F: ATCAAGGGCAAGGAGGTGACAG & 143 \\
& R: GAGTCCAGTGTTGGAGCGATG & \\
BDNF & F: AACCATAAGGACGCGGACTTG & 51 \\
& R: TTGACTGCTGAGCATCACCC & \\
Erk1 & F: TCCCCATAGCCTGAGTGATGAG & 102 \\
& R: CCATTCCAGAACGGTCTACCAGA & \\
Erk2 & F: TCCCAAATGCTGACTCCAAAG & 179 \\
R: AAGTCGTCCAACTCCATGTCAAAC & \\
& F: AGATGTGCGACCCTGGAATGAC & 194 \\
& R: AGTGATGCGGATATAGGCGATGC
\end{tabular}

Actin; NGF, Nerve Growth Factor; BDNF, Brain-Derived Neurotrophic Factor; ERK, Extracellular signal-Regulated Kinases; CaMKIl, Calmodulin-dependent protein kinase II. 
different when $p<0.05$. All results are expressed as mean \pm SEM. Food intake, body weight gain, probe test comparisons (such as the traveled distance in target quadrant, the swim speed during the cued task and the probe test, the platform annulus crossings and the proximity to the platform) and PCR data were analyzed using a 2-way ANOVA (with two factors: age and diet) followed by a post hoc Fisher PLSD test when appropriate. Spatial learning, search strategy, swim speed during the learning phase, swim path efficiency, probe test analysis were analyzed using a 3-way ANOVA with repeated measures (age, diet and days or quadrants) followed by a post hoc Fisher PLSD test when appropriate. Probe test comparisons of each group with chance level $(25 \%)$ were performed with a one-sample $t$-test. For the distance traveled in different quadrants during the probe test, intra-group comparisons were performed using a one-way ANOVA followed by a Dunnett's multiple comparison test.

During the cued phase of the behavioral task, one middleaged control mouse was excluded from the experiment because it was floating and did not look for the platform. During the training phase, five mice (one adult control mouse, two adult supplemented mice, one middle-aged control mouse and one middle-aged supplemented mouse) were excluded from the experiment because they may not have learned that there was an escape platform, therefore they were not searching for it. They were identified thanks to an intra-group outlier analysis on the distance and the latency to reach the platform (mean $\pm 2 \mathrm{SD}$ ).

\section{RESULTS}

\section{Effects of Age and PEGB-Enriched Diet on Food Intake and Weight Gain}

Food intake and weight gain were measured along the 8 weeks of diet exposure. Middle-aged mice consume more food than adult mice whatever the diet as revealed by the 2 -way ANOVA on average food intake (effect of age $\left[F_{(1,32)}=84.451, p<0.0001\right]$, no effect of diet $\left[F_{(1,32)}=0.724\right.$, n.s. $]$ and no age $\times$ diet interaction $\left[F_{(1,32)}=12.387\right.$, n.s. $\left.]\right)$ (Figure 2A).

Adult mice that are completing their full growth gain more weight over the 8 weeks than middle-aged mice regardless of the diet. Indeed, a 2-way ANOVA on average body weight gain revealed an age effect $\left(F_{(1,32)}=20.958, p<0.0001\right)$, no diet effect $\left(F_{(1,32)}=1.587\right.$, n.s. $)$, and no age $\times$ diet interaction $\left(F_{(1,32)}=0.007\right.$, n.s. $)($ Figure 2B).

\section{Effects of Age and PEGB-Enriched Diet on Spatial Learning and Memory}

To acquire the procedural aspects of the task such as swimming and climbing onto the platform and to evaluate visuo-motor capabilities, mice were first trained to find a visible platform in the Morris water maze without distal cues. Middle-aged mice swam slower than adult mice, under a control or a PEGBenriched diet as revealed by an ANOVA performed on the swim speed over the trials in the cued task (age effect $\left[F_{(1,32)}=4.325\right.$, $p<0.05]$, with no effect of diet $\left[F_{(1,32)}=0.354\right.$, n.s. $]$ and no interaction age $\times$ diet $\left[F_{(1,32)}=0.959\right.$, n.s. $]$ ) (data not shown). The same observation has been made during the learning phase (age effect $\left[F_{(1,32)}=17.758, p<0.001\right]$, with no effect of diet $\left[F_{(1,32)}=0.089\right.$, n.s. $]$, no interaction age $\times \operatorname{diet}\left[F_{(1,32)}=1.642\right.$, n.s. and no day effect $\left[F_{(1,96)}=2.648\right.$, n.s. $]$ ) (Figure 3A). As the latency to reach the platform is dependent on the swimming speed, the distance covered to reach the platform was chosen as a more appropriate measure to show the acquisition rate for this cued task and for spatial learning.

In this way, all groups had similar visual capabilities and did not show any impairment in the cued version of the Morris water maze task. Indeed, all groups traveled similar distances to reach the visible platform because the 2-way ANOVA on the distance to reach the visible platform indicated no effect of age $\left(F_{(1,32)}=2.935\right.$, n.s. $)$, no effect of diet $\left(F_{(1,32)}=0.012\right.$, n.s. $)$, and no age $\times$ diet interaction $\left(F_{(1,32)}=0.905\right.$, n.s.) (data not shown).

From day 1, mice were trained in the spatial version of the Morris water maze to test the effects of age and PEGB on spatial learning and memory. The four groups of mice traveled significantly less and less distance over the 4 days (Figure 3B), indicating that all groups learned the platform location (day effect $\left[F_{(3,96)}=39.862, p<0.0001\right]$ ). However, middle-aged mice traveled significantly longer distance than adult mice to find the platform, revealing spatial learning deficits (ANOVA: age effect $\left[F_{(1,32)}=5.256, p<0.05\right]$ ). Moreover, mice that are under a PEGB-enriched diet showed better performance than mice under a control diet (ANOVA: diet effect $\left.\left[F_{(1,32)}=4.182, p<0.05\right]\right)$. Interestingly, there was no interaction age $\times$ diet, suggesting that this diet effect was observed not only in middle-aged supplemented mice which performed as well as adult control mice (ANOVA $\left[F_{(1,32)}=2.137\right.$, n.s. $\left.]\right)$, but also in adult mice that are under the PEGB-enriched diet and seem to perform better especially on the first day of training. On the last training day, all groups traveled similar distance to reach the platform (Figure 3B). These results were confirmed by the analyses on the swim path efficiency. Indeed, the ANOVA similarly revealed a day effect $\left(F_{(1,96)}=44.837, p<0.0001\right)$ an age effect $\left(F_{(1,32)}=8.551, p<0.01\right)$ and a trend for an interaction age $\times$ diet $\left(F_{(1,32)}=3.976, p=0.0547\right)$ and for a diet effect $\left(F_{(1,32)}=3.206, p=0.0828\right)$ (Supplementary Figure 1). Indeed, on the first learning trials, all mice may complete the task by chance (as they have not constructed any cognitive map yet): this could hide the effects of polyphenols in the path efficiency.

Spatial memory was assessed during the probe test. As the swim speed is still affected by age on this trial (Figure 3C), the traveled distance has been chosen as the most appropriate parameter. One sample test comparing to the chance level (25\%) revealed that all groups swam significantly more distance in the target quadrant (adult control: $p<0.05$; adult supplemented: $p<0.05$; middle-aged control: $p<0.05$; middle-aged supplemented: $p<0.01$ ) (Figure 3D), revealing that $72 \mathrm{~h}$ after the last training session, the four groups remembered the location of the platform. Besides, a 2-way ANOVA performed on the percentage of distance traveled in the different quadrants revealed no quadrant $x$ age interaction $\left(F_{(1,96)}=0.395\right.$, n.s. $)$ but a quadrant $\times$ diet 
A

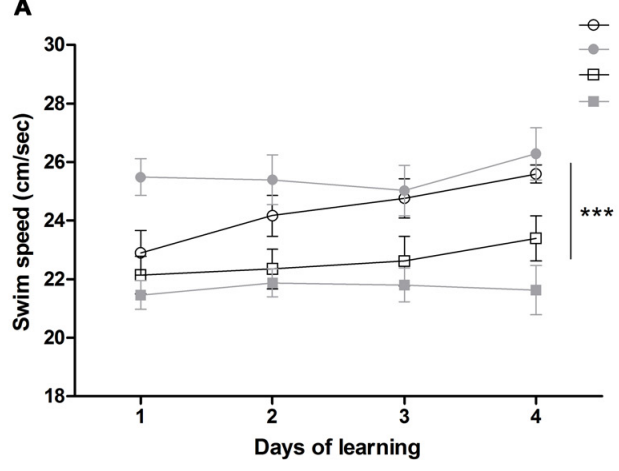

B

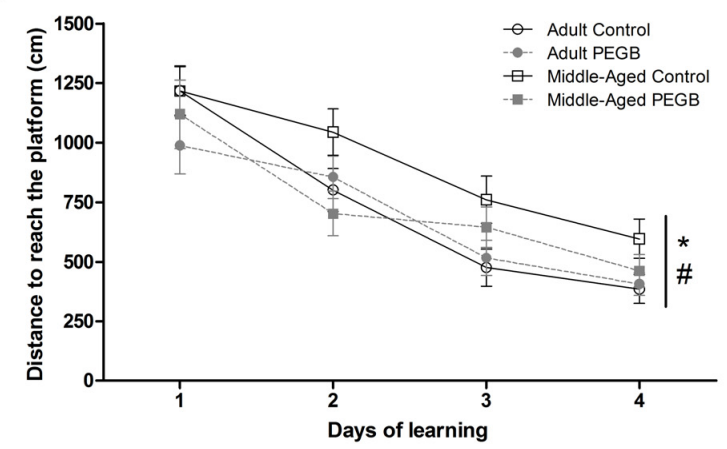

C

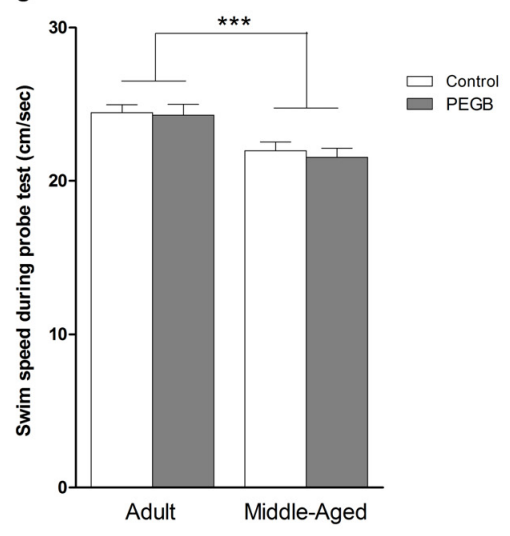

Adult Control

- Adult PEGB

Middle-Aged Control

Middle-Aged PEGB

\section{。}

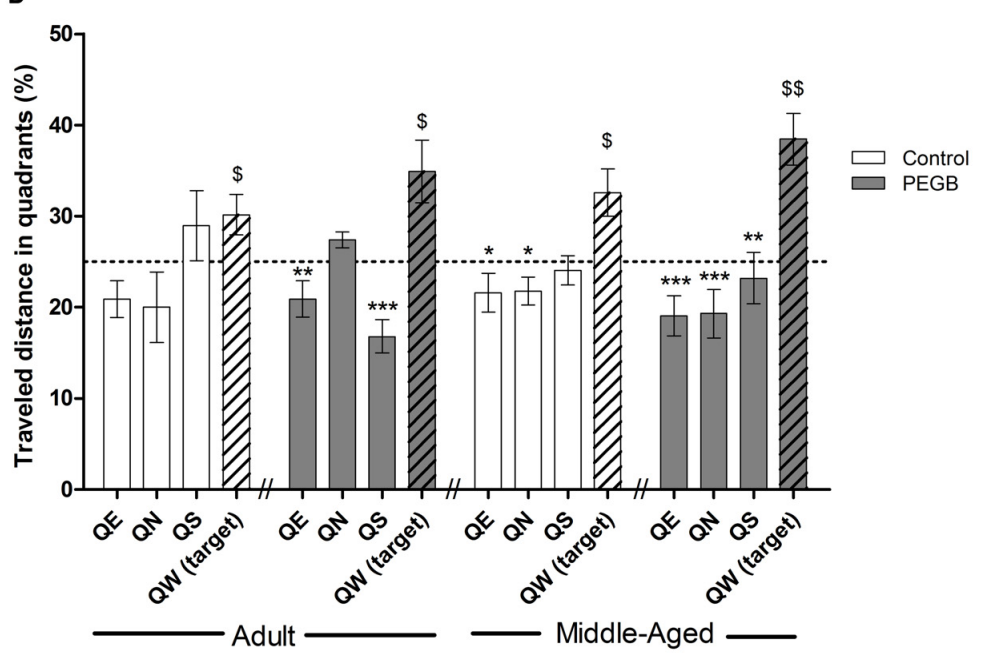

E

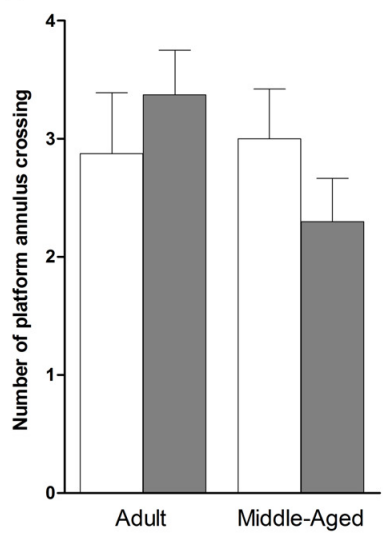

FIGURE 3 | Effects of $\mathbf{8}$ weeks of PEGB supplementation on spatial learning and memory. (A) Swim speed during learning is reduced with aging but not affected by the supplementation with PEGB (age effect: ${ }^{* * *} p<0.001$ by 3 -way ANOVA; $n=9-11$ per group). (B) Distance covered to reach the hidden platform over the four consecutive days of spatial learning (trials are averaged for each training day). Middle-aged mice exhibit longer distance compared to adult mice to reach the platform during the training sessions while mice fed with the PEGB-enriched diet travel less distance to reach the platform than mice under a control diet (day effect $p<0.0001$; age effect ${ }^{*} p<0.05$; diet effect ${ }^{\#} p<0.05$ by 3 -way ANOVA with repeated measures). (C) Swim speed during the probe test is reduced in middle-aged mice (age effect: $\left.{ }^{* * *} p<0.0001\right)$. (D) Percentage of distance traveled in quadrants during the probe test. The dotted line corresponds to chance level (25\%). All groups can remember the platform location traveling preferentially more distance in the target quadrant and the PEGB-enriched diet slightly ameliorates memory performance $\left({ }^{\$} p<0.05,{ }^{\$} p<0.01\right.$ vs. chance level by one sample $t$-test. ${ }^{*} p<0.05,{ }^{* *} p<0.01$, ${ }^{* * *} p<0.001$ compared to QW-Target by One-way ANOVA and Dunnett's multiple comparison test; $n=9-11$ per group). (E) The number of crossings of the platform annulus is not impacted by age nor by PEGB. (F) The mean proximity to the platform is similar for all groups. 

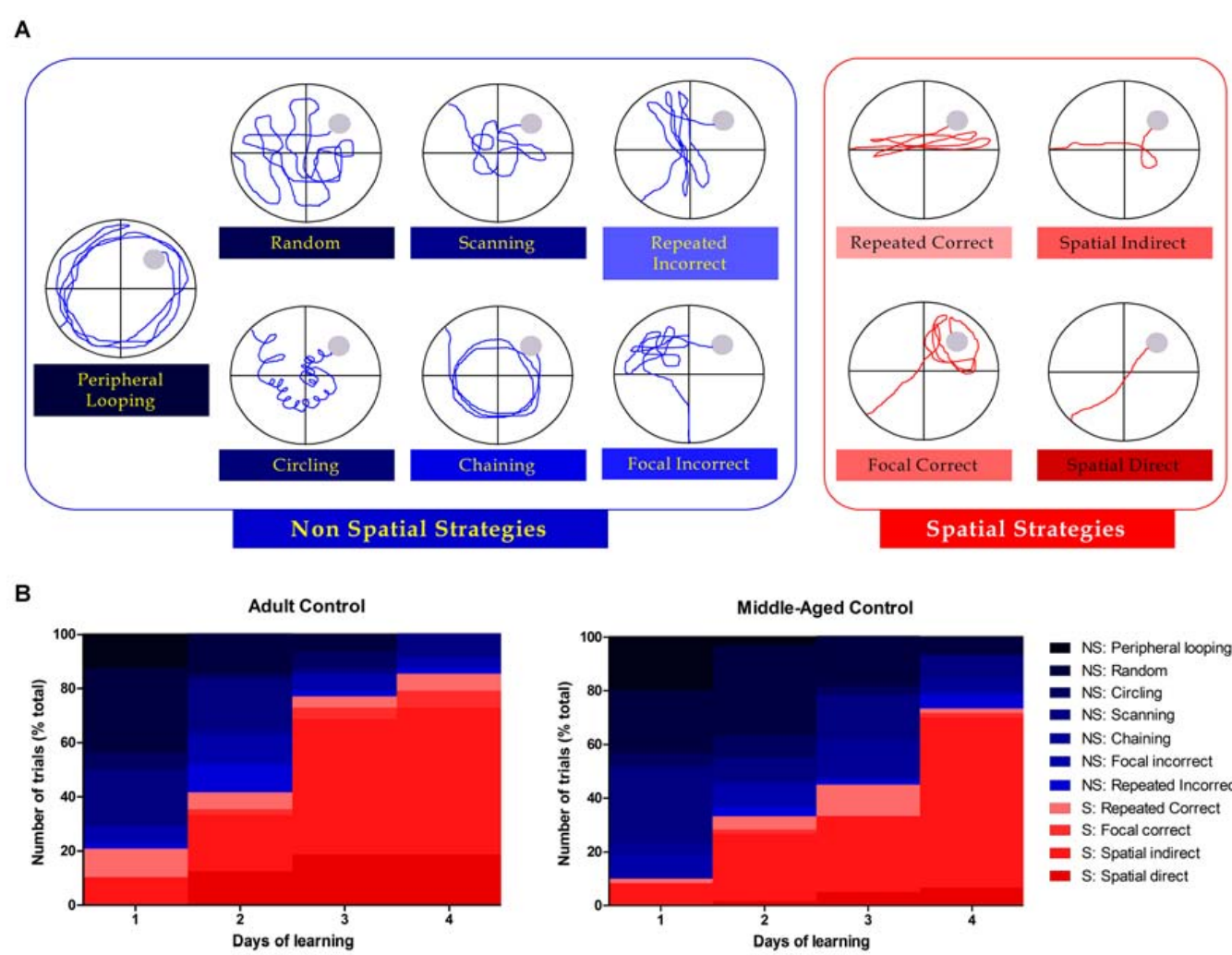

Spatial Strategies
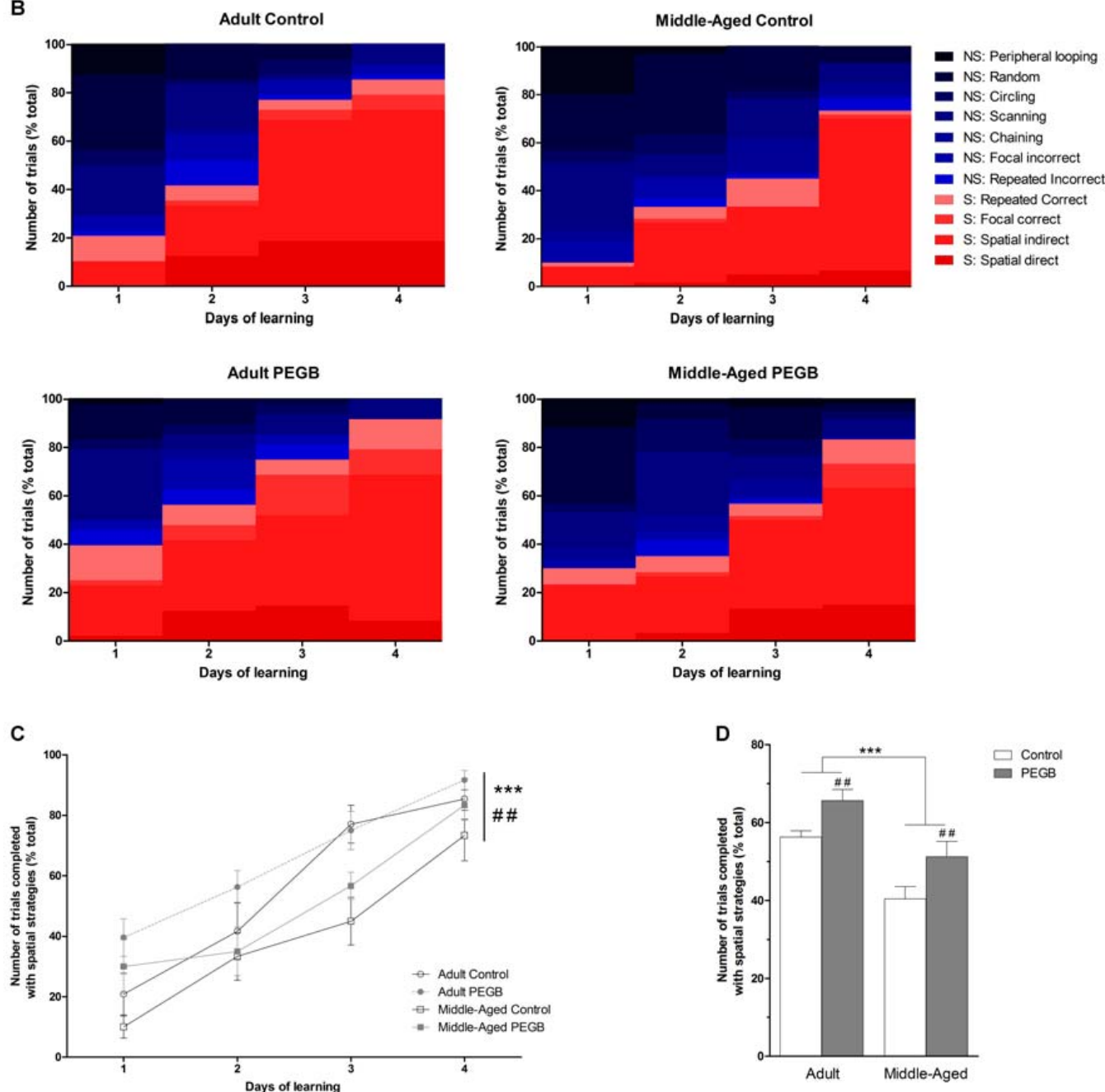

FIGURE 4 | Effects of 8 weeks of PEGB supplementation on search strategies during spatial learning in the Morris water maze. (A) Representative path patterns that reflect "non-spatial" (blue) or "spatial" (red) strategies used to reach the hidden platform (filled gray circle). Operational definitions of individual strategies are described in the method section. (B) Search strategies used during learning. Non-spatial strategies are represented in blue colors and spatial strategies in red colors. (C) All groups show an evolution of the use of non-spatial to spatial strategies (day effect $p<0.0001$ ). An age effect and a diet effect are also observed (age effect: ${ }^{* * *} p<0.0001$; diet effect: ${ }^{\# \#} p<0.01$ ). (D) Adult mice exhibit more use of spatial strategies than middle-aged mice. Moreover mice fed with the PEGB-enriched diet performed more spatial strategies than mice under the control diet (age effect: ${ }^{* * *} p<0.0001$; diet effect: \#\# $p<0.01$ by 3-way ANOVA; $n=9-11$ per group). 
interaction $\left(F_{(1,96)}=3.513, p<0.05\right)$, suggesting that PEGB may improve spatial memory. A one-way ANOVA realized for each group revealed a quadrant effect for the supplemented adult mice $\left(F_{(1,32)}=9.465, p<0.001\right)$, the control middle-aged mice $\left(F_{(1,32)}=5,051, p<0.01\right)$ and the supplemented middle-aged mice $\left(F_{(1,32)}=9.532, p<0.001\right)$. Surprisingly, no quadrant effect was revealed for the adult mice under a control diet $\left(F_{(1,32)}=2.244\right.$, n.s. $)$ as they preferentially traveled within two adjacent quadrants (the target west and the south quadrants). However, as previously described, adult control mice traveled more than $30 \%$ of the total distance in the target quadrant. However, according to additional analyses no differences were revealed by the between-group ANOVA for the number of annulus crossings and the mean proximity to the platform (Figures 3E,F). Thus, the PEGB-enriched diet only slightly improves memory performance in the spatial version of the Morris water maze.

\section{Effects of Age and PEGB-Enriched Diet on Strategies During Spatial Learning}

In order to better characterize the age-induced spatial learning deficits, revealed with the conventional parameters, and whether dietary polyphenols could be beneficial, the navigation path of each trial was qualitatively analyzed (Figures 4A,B). The detailed analysis of navigation path revealed that control mice progressively applied different search strategies along the learning phase. Usually, consistent with previous reports (Janus, 2004; Ruediger et al., 2012), mice first adopt nonspatial strategies, beginning with global search (random swim) and then local search strategies (scanning and chaining). The strategies "focal incorrect" and "repeated incorrect" categorized as non-spatial strategies are in fact intermediate, suggesting that mice may use distal cues in an erroneous manner and that their cognitive map is not fully acquired. Then, spatial strategies (repetition of a direct path, indirect search, focal search, direct swim) appear. However, it is of note that control mice do not always go through all strategies. The increase of the use of spatial strategies evolves continuously but not linearly over the trials and correlates with a decreased average distance to reach the platform.

An evolution from non-spatial to spatial strategies over the learning days of the four groups is observed. Indeed, more and more trials are solved using one of the four spatial strategies (3-way ANOVA on navigation strategies: day effect $\left[F_{(3,96)}=51.242, p<0.0001\right]$ ) (Figure 4C). Moreover, this analysis revealed an age effect $\left(F_{(1,32)}=23.116, p<0.0001\right)$ and a diet effect $\left(F_{(1,32)}=10.345, p<0.01\right)$. These data suggest that middle-aged mice take more time to adopt spatial strategies than adult mice (only 50\% of middle-aged control mice and $60 \%$ of middle-aged supplemented used a spatial strategy on the first day) and that mice under the PEGB-enriched diet are more prone to use spatial strategies than mice under the control diet. This diet effect is principally observed in the first learning day for adult mice where an ANOVA revealed a significant diet effect $\left(F_{(1,32)}=8.114, p<0.001\right)$ (Figure 4C): indeed, $100 \%$ of the adult mice consuming PEGB were able to use one of the spatial strategies within the six first trials whereas only $62.5 \%$ of adult mice under the control diet did so (data not shown).

This is confirmed when all trials over the four learning days are considered (Figure 4D): indeed, compared to adult mice, middle-aged mice used less spatial strategies to complete the task (age effect $\left.\left[F_{(1,32)}=23.116, p<0.0001\right]\right)$. Besides, when mice are under a PEGB-enriched diet, they used more spatial strategies than mice under a control diet (diet effect $\left[F_{(1,32)}=10.345\right.$, $p<0.01])$.

\section{Effects of Age and PEGB-Enriched Diet on Hippocampal and Striatal Gene Expression}

To study the neurobiological correlates associated with the ageinduced spatial deficits and the polyphenol-induced behavioral improvements, the mRNA levels of proteins involved in synaptic plasticity were measured (Figure 5). In the hippocampus a significant increase in NGF mRNA levels was observed both in adult and middle-aged mice fed with PEGB-enriched diet $\left(F_{(1,24)}=4.645, p<0.05\right)$ without being affected by aging (age effect $\left[F_{(1,24)}=0.604\right.$, n.s. $\left.]\right)\left(\right.$ age $\times$ diet effect $\left[F_{(1,24)}=0.239\right.$, n.s.]) (Figure 5A). However, no effect of age or diet was found on the hippocampal BDNF mRNA levels (Figure 5B). The ANOVA on ERK1 mRNA levels revealed an age effect $\left(F_{(1,25)}=7.806\right.$, $p<0.01)$ with an increased expression in middle-aged animals (Figure 5C) whereas no effect of age or diet was observed on the ERK2 mRNA expression (Figure 5D). Moreover, the hippocampal CaMKII mRNA expression is decreased in middleaged mice and could be offset by a supplementation with polyphenols. The ANOVA on hippocampal CaMKII expression revealed an age $\times$ diet interaction $\left(F_{(1,28)}=4.877, p<0.05\right)$ and the post hoc Fisher PLSD test showed a significant difference between the mRNA levels observed in middle-aged control mice and those of the adult control mice $(p<0.05)$, and those of the middle-aged supplemented mice $(p<0.05)$ (Figure 5E).

In order to verify the non-involvement of the striatum in the use of spatial strategies, the expression profile of the same mRNAs was assessed. However, in our conditions, striatal NGF and $B D N F$ mRNA levels were too low to be quantified (data not shown) and no difference in the levels of striatal CaMKII mRNA expression was observed showing that the changes observed in the hippocampus were specific to this structure (Figure 5F).

\section{DISCUSSION}

In the present study, we have shown for the first time that a supplementation with a PEGB ameliorates the profile of spatial navigation learning in the Morris Water maze and by this way slightly improves memory of middleaged mice. Indeed, we evidenced with the categorization of navigation strategies that middle-aged mice take more time to adopt spatial strategies to solve the Morris water maze task. Besides, a supplementation in polyphenols can facilitate the use of spatial strategies by adult and 


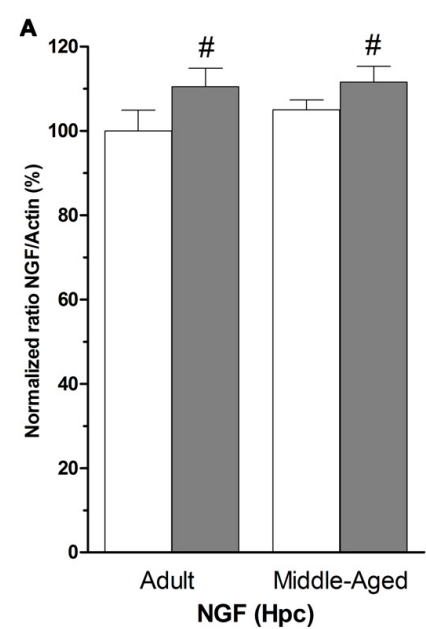

C

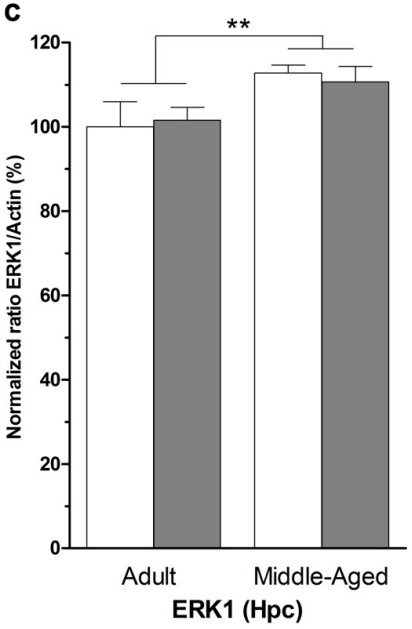

E

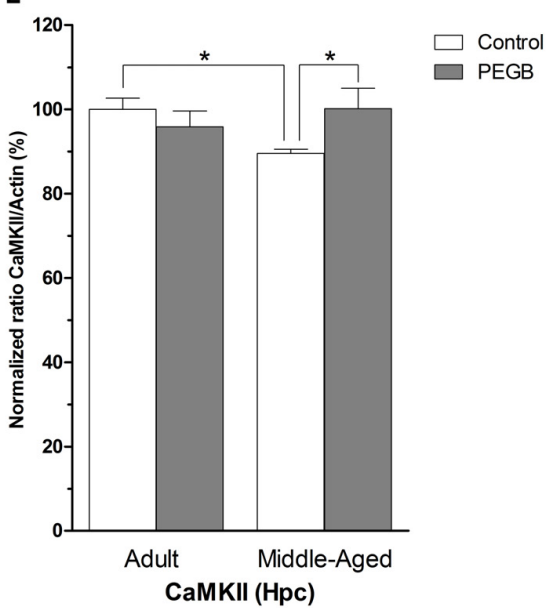

B

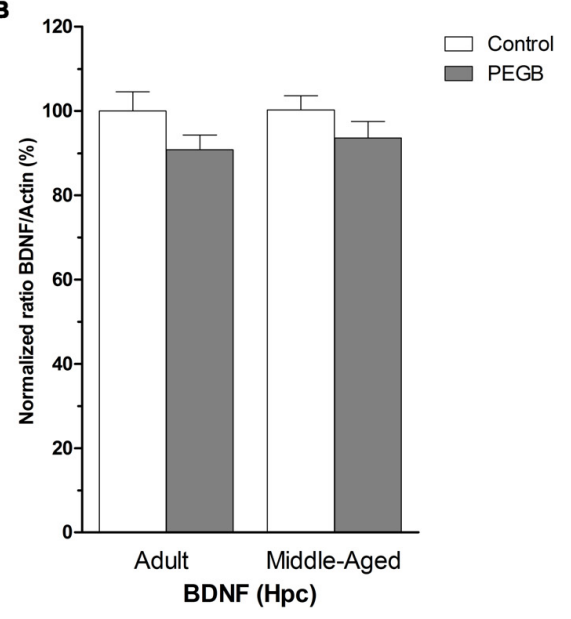

D

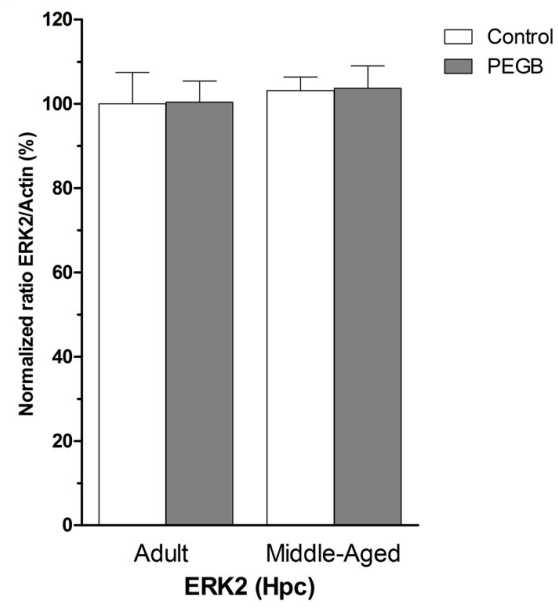

$\mathbf{F}$

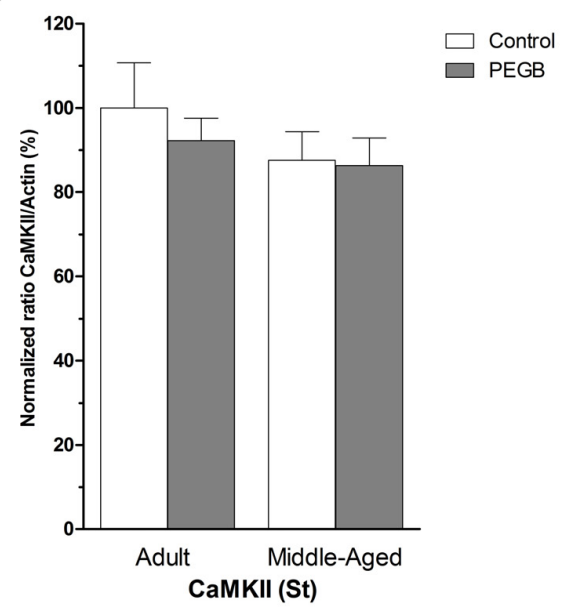

FIGURE 5 | Effects of PEGB supplementation on hippocampal (Hpc) and striatal (St) plasticity-related gene expression. (A,B) NGF mRNA expression increases significantly in the hippocampus of supplemented animals (diet effect ${ }^{\#} p<0.05$ ) but no differences induced by age or diet are found in hippocampal brain derived neurotrophic factor (BDNF) mRNA levels. (C,D) Hippocampal ERK1 mRNA levels are increased with age but not with polyphenols (age effect $\left.{ }^{* *} p<0.01\right)$. No changes in hippocampal ERK2 levels are induced by age nor diet. (E,F) Age decreases CaMKII mRNA levels in the hippocampus which are restored by the PEGB-enriched diet $\left({ }^{*} p<0.05\right)$. However, no differences are observed in the striatum ( $n=6-10$ per group). 
middle-aged mice. Moreover, these learning impairments are associated with decreased hippocampal CaMKII mRNA levels whereas performance improvements can be linked to the restoration of hippocampal CaMKII mRNA levels and to an increased hippocampal NGF expression with the PEGB supplementation.

The Morris water maze is considered as a test of spatial learning and memory (Morris et al., 1982; Morris, 1984) but this task can also be solved by alternative non-spatial strategies. Consistent with previous reports (Morris, 1984; Wolfer and Lipp, 2000; Janus, 2004; Ruediger et al., 2012) adult control mice completed the task using different search strategies along the learning phase, starting from non-spatial strategies, then intermediate strategies like "focal incorrect" and "repeated incorrect" to switch progressively to spatial strategies (notably focal search around the platform and direct swim to the platform). The increase of the use of spatial strategies evolves continuously but not linearly over the trials as mice may alternate non-spatial and spatial strategies over consecutive trials before using almost exclusively spatial strategies. Moreover, we found that this navigation pattern evolution is influenced by age and diet. It is known that the Morris water maze task is particularly sensitive to cognitive deficits related to aging (Frick et al., 1995; Lindner, 1997; Wolff et al., 2002; de Fiebre et al., 2006). Indeed, age would specifically affect spatial allocentric and sequential egocentric strategies in mice (Fouquet et al., 2011). In this study, we have demonstrated for the first time that the evolution from nonspatial to spatial strategies during learning that is particularly delayed with age is promoted with a supplementation in polyphenols.

The analysis of the navigation strategies allows a more thorough knowledge on the acquisition of spatial memory and permits to put on the fore subtle learning differences. Here, longer escape distance to reach the platform traveled by middleaged mice does not reflect a constant random search of the entire surface area of the pool, which would have indicated a complete lack of spatial learning abilities. It rather shows that some middle-aged mice rely on persistent performance of an alternative strategy that is successful to reach the escape platform but that could appear less efficient if the conditions change. Thus middle-aged mice took more trials to switch to spatial strategies; indeed, their first use of spatial strategies would appear later and most of them would not exclusively use spatial strategies even on the last training day. Indeed, the adoption of spatial strategies is already compromised in 12-month old mice (Gil-Mohapel et al., 2013). In the current study, we used 16-18 month old mice as middle-aged mice as they represent a suitable model with mild cognitive deficits for a 2-month nutritional approach (Pepeu, 2004; Bonhomme et al., 2014).

Here, we show that the PEGB can improve spatial learning in both adult and middle-aged mice. Unlike the middle-aged control mice, middle-aged mice that were fed the PEGBenriched diet learned as quickly as adult control mice. The extract supplementation could thus prevent from the occurrence of age-related learning deficits. The different families of polyphenols present in this extract are known to be effective on cognitive functions in particular flavanols (van Praag et al., 2007; Rendeiro et al., 2013a), anthocyanins (Rendeiro et al., 2009, 2013a; Shan et al., 2009; Gazova et al., 2013) and resveratrol (Abraham and Johnson, 2009; Dal-Pan et al., 2011; Harada et al., 2011; Kodali et al., 2015). However, this is the first nutritional intervention with a mix of different polyphenols at low doses that shows a rescue effect on those specific memory deficits.

In this study, it could be hypothesized that hippocampal impairments in middle-aged mice impede the use of spatial strategies: middle-aged mice would thus solve the task using preferentially striatum-dependent strategies (Packard and McGaugh, 1996; Devan et al., 1999; Colombo et al., 2003; Kelleher et al., 2004; Teather et al., 2005). Indeed, when the hippocampus is altered, the spatial navigational strategies may not be possible or too costly. On the contrary, polyphenols could preserve the involvement of the hippocampus so that hippocampus-dependent strategies are promoted and agerelated deficits reduced.

The neurobiological basis for differences in navigation patterns is not fully understood but it could be hypothesized that differential activations of the hippocampus and the striatum during the learning phase could explain this evolution. Indeed, evidence supports the view that the hippocampus and the striatum act in parallel during the acquisition of various tasks (Colombo et al., 2003; Gazova et al., 2013). Indeed, sustained hippocampal expression of Fos is found in mice and rats that predominantly use allocentric strategies (Passino et al., 2002; Colombo et al., 2003) and c-Jun-immunoreactive cells were observed in the striatum of rats that acquired a cued task (Teather et al., 2005). Phosphorylated CREB immunoreactivity (pCREB-IR) is also increased in the hippocampus of rats that use an allocentric spatial strategy to solve a radial arm maze task, whereas pCREB-IR is increased in the striatum of rats that use an egocentric response strategy (Colombo et al., 2003).

The hippocampus dysfunction during aging could particularly be due to reduced persistence and magnitude of long-term potentiation in hippocampal neurons (Barnes, 1979; Barnes and McNaughton, 1985; Deupree et al., 1991; Barnes et al., 1992; Moore et al., 1993; Geinisman et al., 1995; Rosenzweig et al., 1997; Calhoun et al., 1998; Smith et al., 2000). Polyphenols have been shown to impact on different neuronal signaling pathways involved in synaptic plasticity and long term potentiation (Williams and Grayer, 2004; Schroeter et al., 2007; Vauzour et al., 2007; Rendeiro et al., 2009) and particularly on the modulation of specific signaling pathways involved in learning and memory: our results are partially consistent with these studies. Indeed, CaMKII expression that decreases during aging can be recovered by an 8-week polyphenol supplementation. This effect could be attributed to the flavanols, provided mainly from grapes, because a catechin supplementation in aged mice has been shown to restore hippocampal expression level of CaMKII (Abraham and Johnson, 2009) whereas a blueberry supplementation, richer in anthocyanins, failed to 
restore CaMKII activation in aged rats (Rendeiro et al., 2009). Contrary to what might have been expected, we did not observe modifications in ERK2 mRNA expression, whereas there was an increase in ERK1 mRNA expression in middle-aged mice whatever the diet. No modification in mRNA or total protein levels have been described up to now. However, the activation of ERK1/2 has been shown to decrease with aging and to be normalized with polyphenols from blueberry (Rendeiro et al., 2009, 2013a).

Moreover, despite a nutritional approach dealing with low doses of polyphenols, the PEGB used in the present study also permitted to slightly increase hippocampal NGF mRNA expression in both adult and middle-aged mice. Such an increase in NGF expression has previously been associated with an improvement of memory performance particularly in aged rodents (Deupree et al., 1991; Woolf et al., 2001). It could thus be hypothesized that the effects of the polyphenols are supported by this NGF mRNA level increase (De Nicoló et al., 2013) but it may not be the unique factor underlying these effects. However, no modification in BDNF mRNA expression has been observed after an 8-week supplementation in polyphenols although a decrease in $\mathrm{BDNF}$ and pro-BDNF mRNA and proteins levels have been reported during normal aging (Phillips et al., 1991; Michalski and Fahnestock, 2003; Peng et al., 2005; Calabrese et al., 2013) and an increase in BDNF levels could have been observed as previously (Rendeiro et al., 2013a).

In order to evidence the differential activation of the hippocampus and the striatum during learning and to determine how polyphenols could impact on the choice of the used strategy, we have also evaluated gene expression in the striatum, focusing on BDNF, NGF and CaMKII expressions. As NGF and BDNF mRNA expressions were too low to be quantifiable in the striatum, their modulation may not be responsible for the observed behavioral effects. However, unlike in the hippocampus, CaMKII expression in the striatum was not modulated by age nor by polyphenols. These results suggest that the modulation of CaMKII expression is specific to the hippocampus and could be linked to the effect of age and polyphenols on the use of "spatial" strategies.

It would be interesting to know how polyphenols precisely act to modify gene expression. It has been established through the use of autoradiography, that specific polyphenol binding sites for resveratrol exist throughout the rat brain (Han et al., 2006). The action of various polyphenols and resveratrol analogs could be mediated by the activation of common "receptor" binding sites particularly enriched at the level of the cellular plasma membrane in the rat brain. It is though unclear what the molecular nature of those receptors might be (Barco et al., 2006). It has also been reported that the effects of resveratrol could also be linked to its interaction with sirtuins (Borra et al., 2005; Donmez et al., 2010; Sadowska-Bartosz and Bartosz, 2014). Besides, van Praag (2009) has proposed the existence of specific membrane receptors for flavonoids.

The present results show that learning alterations in the early stage of aging can be overcome with a nutritional intervention with polyphenols. Our study focused on spatial learning in mice but other potential effects of dietary polyphenols on other kinds of memory must be studied more thoroughly. Thus, polyphenols are potential food nutrients that can help in the prevention of the age-related cognitive decline (Impey et al., 2004; AndresLacueva et al., 2005; Schroeter et al., 2007; Shukitt-Hale et al., 2008; Abraham and Johnson, 2009; Rendeiro et al., 2009; DalPan et al., 2011; Harada et al., 2011; Kean et al., 2015) and our results suggest that they can play an important role for memory early in life. Furthermore, future investigations are still needed to better determine how polyphenols act at the molecular level to modulate gene expression, which potentially leads to improved cognitive performance. As preventive strategies for healthy aging are being developed, their definition must take into account environmental factors such as nutrition to promote the maintenance of a satisfactory cognitive state in elderly subjects and to avoid -or at least delay-any evolution towards memory loss and dementia (Gómez-Pinilla, 2008; Joseph et al., 2009; van Praag, 2009; Murphy et al., 2014).

\section{AUTHOR CONTRIBUTIONS}

JB, DG, SL, VP and PL conceived and designed the experiments; JB, LS, SA and PL performed the experiments; JB, PL and SA analyzed the data; JB and PL wrote the manuscript.

\section{ACKNOWLEDGMENTS}

This work is part of the Neurophenols project selected in the 12th call for FUI (Fonds Unique Interministériel) projects. The Neurophenols Consortium is a Europe-North America research collaboration dedicated to the research and development of natural ingredients and products to prevent age-related cognitive decline in humans and pets. The Consortium brings together scientists in the fields of phytochemistry, neuroscience, psychology and nutrition with companies specialized in the development of active ingredients and food supplements. The specific aims of the program are to characterize and formulate fruit extracts from blueberry and grape, to evaluate their safety and efficacy in pre-clinical and clinical trials. The project has been supported by Bpifrance, the Aquitaine Regional Council (Conseil Régional d'Aquitaine), and by the European Regional Development Fund (ERDF). The authors would like to thank Mathieu Cadet and Philippe Birac for animal care. We are also grateful to the Neurophenols consortium and to Damien Bonhomme, Maël Guillard and Katia Touyarot for their technical contribution and their comments on the manuscript.

\section{SUPPLEMENTARY MATERIAL}

The Supplementary Material for this article can be found online at: http://journal.frontiersin.org/article/10.3389/fnbeh. 2016.00009/abstract

Supplementary Figure 1 | Swim path efficiency during spatial learning. Swim path efficiency is only affected by age but PEGB-enriched diet tends to improve learning (age effect: ${ }^{* *} p<0.01$; diet effect: $p=0.0828$; age $\times$ diet effect: $p=0.0547$ by 3 -way ANOVA. $n=9-11$ per group). 


\section{REFERENCES}

Abd El Mohsen, M., Bayele, H., Kuhnle, G., Gibson, G., Debnam, E., Kaila Srai, S., et al. (2006). Distribution of [3H]trans-resveratrol in rat tissues following oral administration. Br. J. Nutr. 96, 62-70. doi: 10.1079/bjn20061810

Abd El Mohsen, M. M., Kuhnle, G., Rechner, A. R., Schroeter, H., Rose, S., Jenner, P., et al. (2002). Uptake and metabolism of epicatechin and its access to the brain after oral ingestion. Free Radic. Biol. Med. 33, 1693-1702. doi: 10. 1016/s0891-5849(02)01137-1

Abraham, J., and Johnson, R. W. (2009). Consuming a diet supplemented with resveratrol reduced infection-related neuroinflammation and deficits in working memory in aged mice. Rejuvenation Res. 12, 445-453. doi: 10.1089/rej. 2009.0888

Adrian, M., Jeandet, P., Douillet-Breuil, A. C., Tesson, L., and Bessis, R. (2000). Stilbene content of mature Vitis vinifera berries in response to UV-C elicitation. J. Agric. Food Chem. 48, 6103-6105. doi: 10.1021/jf0009910

Ahmad, A., Khan, M. M., Hoda, M. N., Raza, S. S., Khan, M. B., Javed, H., et al. (2011). Quercetin protects against oxidative stress associated damages in a rat model of transient focal cerebral ischemia and reperfusion. Neurochem. Res. 36, 1360-1371. doi: 10.1007/s11064-011-0458-6

Aiyer, H. S., Warri, A. M., Woode, D. R., Hilakivi-Clarke, L., and Clarke, R. (2012). Influence of berry polyphenols on receptor signaling and cell-death pathways: implications for breast cancer prevention. J. Agric. Food Chem. 60, 5693-5708. doi: 10.1021/jf204084f

Alvarez, V. A., and Sabatini, B. L. (2007). Anatomical and physiological plasticity of dendritic spines. Annu. Rev. Neurosci. 30, 79-97. doi: 10.1146/annurev. neuro.30.051606.094222

Andres-Lacueva, C., Shukitt-Hale, B., Galli, R. L., Jauregui, O., LamuelaRaventos, R. M., and Joseph, J. A. (2005). Anthocyanins in aged blueberry-fed rats are found centrally and may enhance memory. Nutr. Neurosci. 8, 111-120. doi: 10.1080/10284150500078117

Asensi, M., Medina, I., Ortega, A., Carretero, J., Baño, M. C., Obrador, E., et al. (2002). Inhibition of cancer growth by resveratrol is related to its low bioavailability. Free Radic. Biol. Med. 33, 387-398. doi: 10.1016/s08915849(02)00911-5

Asha Devi, S., Sagar Chandrasekar, B. K., Manjula, K. R., and Ishii, N. (2011). Grape seed proanthocyanidin lowers brain oxidative stress in adult and middleaged rats. Exp. Gerontol. 46, 958-964. doi: 10.1016/j.exger.2011.08.006

Bach, M. E., Barad, M., Son, H., Zhuo, M., Lu, Y. F., Shih, R., et al. (1999). Agerelated defects in spatial memory are correlated with defects in the late phase of hippocampal long-term potentiation in vitro and are attenuated by drugs that enhance the cAMP signaling pathway. Proc. Natl. Acad. Sci. U S A 96, 5280-5285. doi: 10.1073/pnas.96.9.5280

Barco, A., Bailey, C. H., and Kandel, E. R. (2006). Common molecular mechanisms in explicit and implicit memory. J. Neurochem. 97, 1520-1533. doi: 10.1111/j. 1471-4159.2006.03870.x

Barnes, C. A. (1979). Memory deficits associated with senescence: a neurophysiological and behavioral study in the rat. J. Comp. Physiol. Psychol. 93, 74-104. doi: 10.1037/h0077579

Barnes, C. A., and McNaughton, B. L. (1985). An age comparison of the rates of acquisition and forgetting of spatial information in relation to longterm enhancement of hippocampal synapses. Behav. Neurosci. 99, 1040-1048. doi: 10.1037/0735-7044.99.6.1040

Barnes, C. A., Rao, G., Foster, T. C., and McNaughton, B. L. (1992). Regionspecific age effects on AMPA sensitivity: electrophysiological evidence for loss of synaptic contacts in hippocampal field CA1. Hippocampus 2, 457-468. doi: 10.1002/hipo.450020413

Barros, D., Amaral, O. B., Izquierdo, I., Geracitano, L., do Carmo Bassols Raseira, M., Henriques, A. T., et al. (2006). Behavioral and genoprotective effects of Vaccinium berries intake in mice. Pharmacol. Biochem. Behav. 84, 229-234. doi: 10.1016/j.pbb.2006.05.001

Bonhomme, D., Pallet, V., Dominguez, G., Servant, L., Henkous, N., Lafenêtre, P., et al. (2014). Retinoic acid modulates intrahippocampal levels of corticosterone in middle-aged mice: consequences on hippocampal plasticity and contextual memory. Front. Aging Neurosci. 6:6. doi: 10.3389/fnagi.2014.00006

Borra, M. T., Smith, B. C., and Denu, J. M. (2005). Mechanism of human SIRT1 activation by resveratrol. J. Biol. Chem. 280, 17187-17195. doi: 10.1074/jbc. m501250200
Bramham, C. R., and Messaoudi, E. (2005). BDNF function in adult synaptic plasticity: the synaptic consolidation hypothesis. Prog. Neurobiol. 76, 99-125. doi: 10.1016/j.pneurobio.2005.06.003

Bramham, C. R., and Wells, D. G. (2007). Dendritic mRNA: transport, translation and function. Nat. Rev. Neurosci. 8, 776-789. doi: 10.1038/nrn2150

Brody, D. L., and Holtzman, D. M. (2006). Morris water maze search strategy analysis in PDAPP mice before and after experimental traumatic brain injury. Exp. Neurol. 197, 330-340. doi: 10.1016/j.expneurol.2005.10.020

Calabrese, F., Guidotti, G., Racagni, G., and Riva, M. A. (2013). Reduced neuroplasticity in aged rats: a role for the neurotrophin brain-derived neurotrophic factor. Neurobiol. Aging 34, 2768-2776. doi: 10.1016/j. neurobiolaging.2013.06.014

Calabrese, F., Molteni, R., Racagni, G., and Riva, M. A. (2009). Neuronal plasticity: a link between stress and mood disorders. Psychoneuroendocrinology 34, S208-S216. doi: 10.1016/j.psyneuen.2009.05.014

Calhoun, M. E., Kurth, D., Phinney, A. L., Long, J. M., Hengemihle, J., Mouton, P. R., et al. (1998). Hippocampal neuron and synaptophysin-positive bouton number in aging C57BL/6 mice. Neurobiol. Aging 19, 599-606. doi: 10. 1016/s0197-4580(98)00098-0

Carew, T. J. (1996). Molecular enhancement of memory formation. Neuron 16, 5-8. doi: 10.1016/s0896-6273(00)80016-1

Cho, J., Kang, J. S., Long, P. H., Jing, J., Back, Y., and Chung, K. S. (2003). Antioxidant and memory enhancing effects of purple sweet potato anthocyanin and cordyceps mushroom extract. Arch. Pharm. Res. 26, 821-825. doi: 10. 1007/bf02980027

Colombo, P. J., Brightwell, J. J., and Countryman, R. A. (2003). Cognitive strategyspecific increases in phosphorylated cAMP response element-binding protein and c-Fos in the hippocampus and dorsal striatum. J. Neurosci. 23, 3547-3554.

Conkright, M. D., Guzmán, E., Flechner, L., Su, A. I., Hogenesch, J. B., and Montminy, M. (2003). Genome-wide analysis of CREB target genes reveals a core promoter requirement for cAMP responsiveness. Mol. Cell 11, 1101-1108. doi: 10.1016/S1097-2765(03)00134-5

Dajas, F., Andrés, A. C., Florencia, A., Carolina, E., and Felicia, R. M. (2013). Neuroprotective actions of flavones and flavonols: mechanisms and relationship to flavonoid structural features. Cent. Nerv. Syst. Agents Med. Chem. 13, 30-35. doi: 10.2174/1871524911313010005

Dajas, F., Rivera, F., Blasina, F., Arredondo, F., Echeverry, C., Lafon, L., et al. (2003). Cell culture protection and in vivo neuroprotective capacity of flavonoids. Neurotox. Res. 5, 425-432. doi: 10.1007/bf03033172

Dal-Pan, A., Pifferi, F., Marchal, J., Picq, J. L., and Aujard, F. (2011). Cognitive performances are selectively enhanced during chronic caloric restriction or resveratrol supplementation in a primate. PLoS One 6:e16581. doi: 10. 1371/journal.pone.0016581

Dash, P. K., Karl, K. A., Colicos, M. A., Prywes, R., and Kandel, E. R. (1991). cAMP response element-binding protein is activated by $\mathrm{Ca} 2+/$ calmodulin- as well as cAMP-dependent protein kinase. Proc. Natl. Acad. Sci. U S A 88, 5061-5065. doi: 10.1073/pnas.88.11.5061

de Fiebre, N. C., Sumien, N., Forster, M. J., and de Fiebre, C. M. (2006). Spatial learning and psychomotor performance of C57BL/6 mice: age sensitivity and reliability of individual differences. Age (Dordr.) 28, 235-253. doi: 10. 1007/s11357-006-9027-3

De Nicoló, S., Tarani, L., Ceccanti, M., Maldini, M., Natella, F., Vania, A., et al. (2013). Effects of olive polyphenols administration on nerve growth factor and brain-derived neurotrophic factor in the mouse brain. Nutrition 29, 681-687. doi: 10.1016/j.nut.2012.11.007

Deupree, D. L., Turner, D. A., and Watters, C. L. (1991). Spatial performance correlates with in vitro potentiation in young and aged Fischer 344 rats. Brain Res. 554, 1-9. doi: 10.1016/0006-8993(91)90164-q

Devan, B. D., McDonald, R. J., and White, N. M. (1999). Effects of medial and lateral caudate-putamen lesions on place- and cue-guided behaviors in the water maze: relation to thigmotaxis. Behav. Brain Res. 100, 5-14. doi: 10. 1016/s0166-4328(98)00107-7

Devi, A., Jolitha, A. B., and Ishii, N. (2006). Grape seed proanthocyanidin extract (GSPE) and antioxidant defense in the brain of adult rats. Med. Sci. Monit. 12, BR124-BR129.

Dinges, D. F. (2006). Cocoa flavanols, cerebral blood flow, cognition and health: going forward. J. Cardiovasc. Pharmacol. 47, S221-S223. doi: 10 1097/00005344-200606001-00019 
Donmez, G., Wang, D., Cohen, D. E., and Guarente, L. (2010). SIRT1 suppresses beta-amyloid production by activating the alpha-secretase gene ADAM10. Cell 142, 320-332. doi: 10.1016/j.cell.2010.06.020

Erickson, C. A., and Barnes, C. A. (2003). The neurobiology of memory changes in normal aging. Exp. Gerontol. 38, 61-69. doi: 10.1016/s0531-5565(02)00160-2

Evans, D. A., Funkenstein, H. H., Albert, M. S., Scherr, P. A., Cook, N. R., Chown, M. J., et al. (1989). Prevalence of Alzheimer's disease in a community population of older persons. Higher than previously reported. JAMA 262, 2551-2556. doi: 10.1001/jama.1989.03430180093036

Finkbeiner, S. (2000). CREB couples neurotrophin signals to survival messages. Neuron 25, 11-14. doi: 10.1016/s0896-6273(00)80866-1

Finkbeiner, S., Tavazoie, S. F., Maloratsky, A., Jacobs, K. M., Harris, K. M., and Greenberg, M. E. (1997). CREB: a major mediator of neuronal neurotrophin responses. Neuron 19, 1031-1047. doi: 10.1016/s0896-6273(00)80395-5

Fouquet, C., Petit, G. H., Auffret, A., Gaillard, E., Rovira, C., Mariani, J., et al. (2011). Early detection of age-related memory deficits in individual mice. Neurobiol. Aging 32, 1881-1895. doi: 10.1016/j.neurobiolaging.2009.11.001

Frick, K. M., Baxter, M. G., Markowska, A. L., Olton, D. S., and Price, D. L. (1995). Age-related spatial reference and working memory deficits assessed in the water maze. Neurobiol. Aging 16, 149-160. doi: 10.1016/0197-4580(94)00155-3

Gallagher, M., and Rapp, P. R. (1997). The use of animal models to study the effects of aging on cognition. Annu. Rev. Psychol. 48, 339-370. doi: 10.1146/annurev. psych.48.1.339

Garthe, A., Behr, J., and Kempermann, G. (2009). Adult-generated hippocampal neurons allow the flexible use of spatially precise learning strategies. PLoS One 4:e5464. doi: 10.1371/journal.pone.0005464

Gazova, I., Laczó, J., Rubinova, E., Mokrisova, I., Hyncicova, E., Andel, R., et al. (2013). Spatial navigation in young versus older adults. Front. Aging Neurosci. 5:94. doi: 10.3389/fnagi.2013.00094

Geinisman, Y., Detoledo-Morrell, L., Morrell, F., and Heller, R. E. (1995). Hippocampal markers of age-related memory dysfunction: behavioral, electrophysiological and morphological perspectives. Prog. Neurobiol. 45, 223-252. doi: 10.1016/0301-0082(94)00047-1

Gil-Mohapel, J., Brocardo, P. S., Choquette, W., Gothard, R., Simpson, J. M., and Christie, B. R. (2013). Hippocampal neurogenesis levels predict WATERMAZE search strategies in the aging brain. PLoS One 8:e75125. doi: 10.1371/journal. pone. 0075125

Gómez-Pinilla, F. (2008). Brain foods: the effects of nutrients on brain function. Nat. Rev. Neurosci. 9, 568-578. doi: 10.1038/nrn2421

Han, Y. S., Bastianetto, S., Dumont, Y., and Quirion, R. (2006). Specific plasma membrane binding sites for polyphenols, including resveratrol, in the rat brain. J. Pharmacol. Exp. Ther. 318, 238-245. doi: 10.1124/jpet.106.102319

Haque, A. M., Hashimoto, M., Katakura, M., Tanabe, Y., Hara, Y., and Shido, O. (2006). Long-term administration of green tea catechins improves spatial cognition learning ability in rats. J. Nutr. 136, 1043-1047.

Harada, N., Zhao, J., Kurihara, H., Nakagata, N., and Okajima, K. (2011). Resveratrol improves cognitive function in mice by increasing production of insulin-like growth factor-I in the hippocampus. J. Nutr. Biochem. 22, 1150-1159. doi: 10.1016/j.jnutbio.2010.09.016

Harris, K. M., and Kater, S. B. (1994). Dendritic spines: cellular specializations imparting both stability and flexibility to synaptic function. Annu. Rev. Neurosci. 17, 341-371. doi: 10.1146/annurev.neuro.17.1.341

Impey, S., Mark, M., Villacres, E. C., Poser, S., Chavkin, C., and Storm, D. R. (1996). Induction of CRE-mediated gene expression by stimuli that generate long-lasting LTP in area CA1 of the hippocampus. Neuron 16, 973-982. doi: 10. 1016/s0896-6273(00)80120-8

Impey, S., McCorkle, S. R., Cha-Molstad, H., Dwyer, J. M., Yochum, G. S., Boss, J. M., et al. (2004). Defining the CREB regulon: a genome-wide analysis of transcription factor regulatory regions. Cell 119, 1041-1054. doi: 10. 1016/s0092-8674(04)01159-6

Impey, S., Smith, D. M., Obrietan, K., Donahue, R., Wade, C., and Storm, D. R. (1998). Stimulation of cAMP response element (CRE)-mediated transcription during contextual learning. Nat. Neurosci. 1, 595-601. doi: 10.1038/2830

Janus, C. (2004). Search strategies used by APP transgenic mice during navigation in the Morris water maze. Learn. Mem. 11, 337-346. doi: 10.1101/lm.70104

Joseph, J., Cole, G., Head, E., and Ingram, D. (2009). Nutrition, brain aging and neurodegeneration. J. Neurosci. 29, 12795-12801. doi: 10.1523/jneurosci.352009.2009
Joseph, J. A., Fisher, D. R., Cheng, V., Rimando, A. M., and Shukitt-Hale, B. (2008). Cellular and behavioral effects of stilbene resveratrol analogues: implications for reducing the deleterious effects of aging. J. Agric. Food Chem. 56, 10544-10551. doi: 10.1021/jf802279h

Juan, M. E., Maijó, M., and Planas, J. M. (2010). Quantification of trans-resveratrol and its metabolites in rat plasma and tissues by HPLC. J. Pharm. Biomed. Anal. 51, 391-398. doi: 10.1016/j.jpba.2009.03.026

Kandel, E. R. (2001). The molecular biology of memory storage: a dialogue between genes and synapses. Science 294, 1030-1038. doi: 10.1126/science. 1067020

Kaur, T., Pathak, C. M., Pandhi, P., and Khanduja, K. L. (2008). Effects of green tea extract on learning, memory, behavior and acetylcholinesterase activity in young and old male rats. Brain Cogn. 67, 25-30. doi: 10.1016/j.bandc.2007.10. 003

Kean, R. J., Lamport, D. J., Dodd, G. F., Freeman, J. E., Williams, C. M., Ellis, J. A., et al. (2015). Chronic consumption of flavanone-rich orange juice is associated with cognitive benefits: an 8-wk, randomized, double-blind, placebo-controlled trial in healthy older adults. Am. J. Clin. Nutr. 101, 506-514. doi: 10.3945/ajcn. 114.088518

Kelleher, R. J. III, Govindarajan, A., and Tonegawa, S. (2004). Translational regulatory mechanisms in persistent forms of synaptic plasticity. Neuron 44, 59-73. doi: 10.1016/j.neuron.2004.09.013

Kim, J. J., Lee, H. J., Han, J. S., and Packard, M. G. (2001). Amygdala is critical for stress-induced modulation of hippocampal long-term potentiation and learning. J. Neurosci. 21, 5222-5228.

Kodali, M., Parihar, V. K., Hattiangady, B., Mishra, V., Shuai, B., and Shetty, A. K. (2015). Resveratrol prevents age-related memory and mood dysfunction with increased hippocampal neurogenesis and microvasculature and reduced glial activation. Sci. Rep. 5:8075. doi: 10.1038/srep08075

Krikorian, R., Boespflug, E. L., Fleck, D. E., Stein, A. L., Wightman, J. D., Shidler, M. D., et al. (2012). Concord grape juice supplementation and neurocognitive function in human aging. J. Agric. Food Chem. 60, 5736-5742. doi: 10.1021/jf300277g

Krikorian, R., Nash, T. A., Shidler, M. D., Shukitt-Hale, B., and Joseph, J. A. (2010a). Concord grape juice supplementation improves memory function in older adults with mild cognitive impairment. Br. J. Nutr. 103, 730-734. doi: 10. 1017/s0007114509992364

Krikorian, R., Shidler, M. D., Nash, T. A., Kalt, W., Vinqvist-Tymchuk, M. R., Shukitt-Hale, B., et al. (2010b). Blueberry supplementation improves memory in older adults. J. Agric. Food Chem. 58, 3996-4000. doi: 10.1021/jf90 29332

Lai, Z. C., Moss, M. B., Killiany, R. J., Rosene, D. L., and Herndon, J. G. (1995). Executive system dysfunction in the aged monkey: spatial and object reversal learning. Neurobiol. Aging 16, 947-954. doi: 10.1016/0197-4580(95)02014-4

Letenneur, L., Proust-Lima, C., Le Gouge, A., Dartigues, J. F., and BarbergerGateau, P. (2007). Flavonoid intake and cognitive decline over a 10-year period. Am. J. Epidemiol. 165, 1364-1371. doi: 10.1093/aje/kwm036

Lindner, M. D. (1997). Reliability, distribution, and validity of age-related cognitive deficits in the Morris water maze. Neurobiol. Learn. Mem. 68, 203-220. doi: 10.1006/nlme.1997.3782

Maei, H. R., Zaslavsky, K., Teixeira, C. M., and Frankland, P. W. (2009). What is the most sensitive measure of water maze probe test performance? Front. Integr. Neurosci. 3:4. doi: 10.3389/neuro.07.004.2009

Margalef, M., Pons, Z., Muguerza, B., and Arola-Arnal, A. (2014). A rapid method to determine colonic microbial metabolites derived from grape flavanols in rat plasma by liquid chromatography-tandem mass spectrometry. J. Agric. Food Chem. 62, 7698-7706. doi: 10.1021/jf5019752

Markowska, A. L., Stone, W. S., Ingram, D. K., Reynolds, J., Gold, P. E., Conti, L. H., et al. (1989). Individual differences in aging: behavioral and neurobiological correlates. Neurobiol. Aging 10, 31-43. doi: 10.1016/s01974580(89)80008-9

Martel, G., Blanchard, J., Mons, N., Gastambide, F., Micheau, J., and Guillou, J. L. (2007). Dynamic interplays between memory systems depend on practice: the hippocampus is not always the first to provide solution. Neuroscience 150, 743-753. doi: 10.1016/j.neuroscience.2007.10.004

Martin, K. C., Barad, M., and Kandel, E. R. (2000). Local protein synthesis and its role in synapse-specific plasticity. Curr. Opin. Neurobiol. 10, 587-592. doi: 10. 1016/s0959-4388(00)00128-8 
Michalski, B., and Fahnestock, M. (2003). Pro-brain-derived neurotrophic factor is decreased in parietal cortex in Alzheimer's disease. Brain Res. Mol. Brain Res. 111, 148-154. doi: 10.1016/s0169-328x(03)00003-2

Milbury, P. E., and Kalt, W. (2010). Xenobiotic metabolism and berry flavonoid transport across the blood-brain barrier. J. Agric. Food Chem. 58, 3950-3956. doi: 10.1021/jf903529m

Moore, C. I., Browning, M. D., and Rose, G. M. (1993). Hippocampal plasticity induced by primed burst, but not long-term potentiation, stimulation is impaired in area CA1 of aged Fischer 344 rats. Hippocampus 3, 57-66. doi: 10. 1002/hipo.450030106

Morris, R. (1984). Developments of a water-maze procedure for studying spatial learning in the rat. J. Neurosci. Methods 11, 47-60. doi: 10.1016/01650270(84)90007-4

Morris, R. G., Garrud, P., Rawlins, J. N., and O'Keefe, J. (1982). Place navigation impaired in rats with hippocampal lesions. Nature 297, 681-683. doi: 10. 1038/297681a0

Murphy, T., Dias, G. P., and Thuret, S. (2014). Effects of diet on brain plasticity in animal and human studies: mind the gap. Neural Plast. 2014:563160. doi: 10. $1155 / 2014 / 563160$

Packard, M. G., and McGaugh, J. L. (1996). Inactivation of hippocampus or caudate nucleus with lidocaine differentially affects expression of place and response learning. Neurobiol. Learn. Mem. 65, 65-72. doi: 10.1006/nlme.1996. 0007

Passino, E., Middei, S., Restivo, L., Bertaina-Anglade, V., and AmmassariTeule, M. (2002). Genetic approach to variability of memory systems: analysis of place vs. response learning and fos-related expression in hippocampal and striatal areas of C57BL/6 and DBA/2 mice. Hippocampus 12, 63-75. doi: 10. 1002/hipo.10007.abs

Peng, S., Wuu, J., Mufson, E. J., and Fahnestock, M. (2005). Precursor form of brain-derived neurotrophic factor and mature brain-derived neurotrophic factor are decreased in the pre-clinical stages of Alzheimer's disease. J. Neurochem. 93, 1412-1421. doi: 10.1111/j.1471-4159.2005.03135.x

Pepeu, G. (2004). Mild cognitive impairment: animal models. Dialogues Clin. Neurosci. 6, 369-377.

Pham, T. A., Impey, S., Storm, D. R., and Stryker, M. P. (1999). CRE-mediated gene transcription in neocortical neuronal plasticity during the developmental critical period. Neuron 22, 63-72. doi: 10.1016/s0896-6273(00)80679-0

Phillips, H. S., Hains, J. M., Armanini, M., Laramee, G. R., Johnson, S. A., and Winslow, J. W. (1991). BDNF mRNA is decreased in the hippocampus of individuals with Alzheimer's disease. Neuron 7, 695-702. doi: 10.1016/08966273(91)90273-3

Poo, M. M. (2001). Neurotrophins as synaptic modulators. Nat. Rev. Neurosci. 2, 24-32. doi: 10.1038/35049004

Prasain, J. K., Peng, N., Dai, Y., Moore, R., Arabshahi, A., Wilson, L., et al. (2009). Liquid chromatography tandem mass spectrometry identification of proanthocyanidins in rat plasma after oral administration of grape seed extract. Phytomedicine 16, 233-243. doi: 10.1016/j.phymed.2008.08.006

Pruunsild, P., Sepp, M., Orav, E., Koppel, I., and Timmusk, T. (2011). Identification of cis-elements and transcription factors regulating neuronal activity-dependent transcription of human BDNF gene. J. Neurosci. 31, 3295-3308. doi: 10.1523/JNEUROSCI.4540-10.2011

Ramirez, M. R., Izquierdo, I., do Carmo Bassols Raseira, M., Zuanazzi, J. A., Barros, D., and Henriques, A. T. (2005). Effect of lyophilised Vaccinium berries on memory, anxiety and locomotion in adult rats. Pharmacol. Res. 52, 457-462. doi: 10.1016/j.phrs.2005.07.003

Rendeiro, C., Foley, A., Lau, V. C., Ring, R., Rodriguez-Mateos, A., Vauzour, D., et al. (2013a). A role for hippocampal PSA-NCAM and NMDA-NR2B receptor function in flavonoid-induced spatial memory improvements in young rats. Neuropharmacology 79C, 335-344. doi: 10.1016/j.neuropharm.2013. 12.003

Rendeiro, C., Vauzour, D., Rattray, M., Waffo-Téguo, P., Merillon, J. M., Butler, L. T., et al. (2013b). Dietary levels of pure flavonoids improve spatial memory performance and increase hippocampal brain-derived neurotrophic factor. PLoS One 8:e63535. doi: 10.1371/journal.pone.0063535

Rendeiro, C., Spencer, J. P., Vauzour, D., Butler, L. T., Ellis, J. A., and Williams, C. M. (2009). The impact of flavonoids on spatial memory in rodents: from behaviour to underlying hippocampal mechanisms. Genes Nutr. 4, 251-270. doi: 10.1007/s12263-009-0137-2
Rimando, A. M., Cuendet, M., Desmarchelier, C., Mehta, R. G., Pezzuto, J. M., and Duke, S. O. (2002). Cancer chemopreventive and antioxidant activities of pterostilbene, a naturally occurring analogue of resveratrol. J. Agric. Food Chem. 50, 3453-3457. doi: 10.1021/jf0116855

Rivera, F., Urbanavicius, J., Gervaz, E., Morquio, A., and Dajas, F. (2004). Some aspects of the in vivo neuroprotective capacity of flavonoids: bioavailability and structure-activity relationship. Neurotox. Res. 6, 543-553. doi: 10. 1007/bf03033450

Rosenzweig, E. S., Rao, G., McNaughton, B. L., and Barnes, C. A. (1997). Role of temporal summation in age-related long-term potentiation-induction deficits. Hippocampus 7, 549-558. doi: 10.1002/(sici)1098-1063(1997)7:5<549::aidhipo $10>3.0$. co; $2-0$

Ruediger, S., Spirig, D., Donato, F., and Caroni, P. (2012). Goal-oriented searching mediated by ventral hippocampus early in trial-and-error learning. Nat. Neurosci. 15, 1563-1571. doi: 10.1038/nn.3224

Sadowska-Bartosz, I., and Bartosz, G. (2014). Effect of antioxidants supplementation on aging and longevity. Biomed Res. Int. 2014:404680. doi: $10.1155 / 2014 / 404680$

Schinder, A. F., and Poo, M. (2000). The neurotrophin hypothesis for synaptic plasticity. Trends Neurosci. 23, 639-645. doi: 10.1016/s0166-2236(00)01672-6

Schroeter, H., Bahia, P., Spencer, J. P., Sheppard, O., Rattray, M., Cadenas, E., et al. (2007). (-)Epicatechin stimulates ERK-dependent cyclic AMP response element activity and up-regulates GluR2 in cortical neurons. J. Neurochem. 101, 1596-1606. doi: 10.1111/j.1471-4159.2006.04434.x

Shan, Q., Lu, J., Zheng, Y., Li, J., Zhou, Z., Hu, B., et al. (2009). Purple sweet potato color ameliorates cognition deficits and attenuates oxidative damage and inflammation in aging mouse brain induced by d-galactose. J. Biomed. Biotechnol. 2009:564737. doi: 10.1155/2009/564737

Shukitt-Hale, B., Carey, A., Simon, L., Mark, D. A., and Joseph, J. A. (2006). Effects of Concord grape juice on cognitive and motor deficits in aging. Nutrition 22 , 295-302. doi: 10.1016/j.nut.2005.07.016

Shukitt-Hale, B., Lau, F. C., and Joseph, J. A. (2008). Berry fruit supplementation and the aging brain. J. Agric. Food Chem. 56, 636-641. doi: 10.1021/jf0 $72505 f$

Smith, T. D., Adams, M. M., Gallagher, M., Morrison, J. H., and Rapp, P. R. (2000). Circuit-specific alterations in hippocampal synaptophysin immunoreactivity predict spatial learning impairment in aged rats. J. Neurosci. 20, 6587-6593.

Sossin, W. S. (2008). Defining memories by their distinct molecular traces. Trends Neurosci. 31, 170-175. doi: 10.1016/j.tins.2008.01.001

Stone, S. S., Teixeira, C. M., Devito, L. M., Zaslavsky, K., Josselyn, S. A., Lozano, A. M., et al. (2011). Stimulation of entorhinal cortex promotes adult neurogenesis and facilitates spatial memory. J. Neurosci. 31, 13469-13484. doi: 10.1523/JNEUROSCI.3100-11.2011

Sweatt, J. D. (2001). The neuronal MAP kinase cascade: a biochemical signal integration system subserving synaptic plasticity and memory. J. Neurochem. 76, 1-10. doi: 10.1046/j.1471-4159.2001.00054.x

Sweatt, J. D. (2004). Mitogen-activated protein kinases in synaptic plasticity and memory. Curr. Opin. Neurobiol. 14, 311-317. doi: 10.1016/j.conb.2004.04.001

Teather, L. A., Packard, M. G., Smith, D. E., Ellis-Behnke, R. G., and Bazan, N. G. (2005). Differential induction of c-Jun and Fos-like proteins in rat hippocampus and dorsal striatum after training in two water maze tasks. Neurobiol. Learn. Mem. 84, 75-84. doi: 10.1016/j.nlm.2005.03.006

Touyarot, K., Bonhomme, D., Roux, P., Alfos, S., Lafenêtre, P., Richard, E., et al. (2013). A mid-life vitamin A supplementation prevents age-related spatial memory deficits and hippocampal neurogenesis alterations through CRABPI. PLoS One 8:e72101. doi: 10.1371/journal.pone.0072101

Uttl, B., and Graf, P. (1993). Episodic spatial memory in adulthood. Psychol. Aging 8, 257-273. doi: 10.1037/0882-7974.8.2.257

van Praag, H. (2009). Exercise and the brain: something to chew on. Trends Neurosci. 32, 283-290. doi: 10.1016/j.tins.2008.12.007

van Praag, H., Lucero, M. J., Yeo, G. W., Stecker, K., Heivand, N., Zhao, C., et al. (2007). Plant-derived flavanol (-)epicatechin enhances angiogenesis and retention of spatial memory in mice. J. Neurosci. 27, 5869-5878. doi: 10. 1523/JNEUROSCI.0914-07.2007

Vauzour, D., Vafeiadou, K., Corona, G., Pollard, S. E., Tzounis, X., and Spencer, J. P. (2007). Champagne wine polyphenols protect primary cortical neurons against peroxynitrite-induced injury. J. Agric. Food Chem. 55, 2854-2860. doi: 10.1021/jf063304z 
Wilkniss, S. M., Jones, M. G., Korol, D. L., Gold, P. E., and Manning, C. A. (1997). Age-related differences in an ecologically based study of route learning. Psychol. Aging 12, 372-375. doi: 10.1037/0882-7974.12.2.372

Williams, C. M., El Mohsen, M. A., Vauzour, D., Rendeiro, C., Butler, L. T., Ellis, J. A., et al. (2008). Blueberry-induced changes in spatial working memory correlate with changes in hippocampal CREB phosphorylation and brainderived neurotrophic factor (BDNF) levels. Free Radic. Biol. Med. 45, 295-305. doi: 10.1016/j.freeradbiomed.2008.04.008

Williams, C. A., and Grayer, R. J. (2004). Anthocyanins and other flavonoids. Nat. Prod. Rep. 21, 539-573. doi: 10.1002/chin.200447250

Witte, A. V., Kerti, L., Margulies, D. S., and Flöel, A. (2014). Effects of resveratrol on memory performance, hippocampal functional connectivity and glucose metabolism in healthy older adults. J. Neurosci. 34, 7862-7870. doi: 10. 1523/jneurosci.0385-14.2014

Wolfer, D. P., and Lipp, H. P. (2000). Dissecting the behaviour of transgenic mice: is it the mutation, the genetic background, or the environment? Exp. Physiol. 85, 627-634. doi: 10.1111/j.1469-445x.2000.02095.x

Wolff, M., Savova, M., Malleret, G., Segu, L., and Buhot, M. C. (2002). Differential learning abilities of $129 \mathrm{~T} 2 / \mathrm{Sv}$ and $\mathrm{C} 57 \mathrm{BL} / 6 \mathrm{~J}$ mice as assessed in three water maze protocols. Behav. Brain Res. 136, 463-474. doi: 10.1016/s01664328(02)00192-4
Woolf, N. J., Milov, A. M., Schweitzer, E. S., and Roghani, A. (2001). Elevation of nerve growth factor and antisense knockdown of TrkA receptor during contextual memory consolidation. J. Neurosci. 21, 1047-1055.

Yan, J. J., Cho, J. Y., Kim, H. S., Kim, K. L., Jung, J. S., Huh, S. O., et al. (2001). Protection against $\beta$-amyloid peptide toxicity in vivo with long-term administration of ferulic acid. Br. J. Pharmacol. 133, 89-96. doi: 10.1038/sj.bjp. 0704047

Conflict of Interest Statement: The authors declare that the research was conducted in the absence of any commercial or financial relationships that could be construed as a potential conflict of interest.

Copyright (c) 2016 Bensalem, Servant, Alfos, Gaudout, Layé, Pallet and Lafenetre. This is an open-access article distributed under the terms of the Creative Commons Attribution License (CC BY). The use, distribution and reproduction in other forums is permitted, provided the original author(s) or licensor are credited and that the original publication in this journal is cited, in accordance with accepted academic practice. No use, distribution or reproduction is permitted which does not comply with these terms. 